\title{
ERS/EACTS statement on the management of malignant pleural effusions
}

\author{
Anna C. Bibby ${ }^{1,2}$, Patrick Dorn ${ }^{3}$, Ioannis Psallidas ${ }^{4}$, Jose M. Porcel ${ }^{5}$, \\ Julius Janssen ${ }^{6}$, Marios Froudarakis ${ }^{7}$, Dragan Subotic ${ }^{8}$, Phillippe Astoul ${ }^{9}$, \\ Peter Licht ${ }^{10}$, Ralph Schmid ${ }^{3}$, Arnaud Scherpereel ${ }^{11}$, Najib M. Rahman ${ }^{4,12}$, \\ Giuseppe Cardillo ${ }^{13,14}$ and Nick A. Maskell ${ }^{1,2,14}$
}

\begin{abstract}
Affiliations: ${ }^{1}$ Academic Respiratory Unit, University of Bristol Medical School Translational Health Sciences, Bristol, UK. ${ }^{2}$ North Bristol Lung Centre, North Bristol NHS Trust, Bristol, UK. ${ }^{3}$ Division of Thoracic Surgery, University Hospital Bern, Bern, Switzerland. ${ }^{4}$ Oxford Respiratory Trials Unit, University of Oxford, Oxford, UK. ${ }^{5}$ Pleural Medicine Unit, Arnau de Vilanova University Hospital, IRB Lleida, Lleida, Spain. ${ }^{6}$ Dept of Pulmonary Diseases, Canisius Wilhelmina Hospital, Nijmegen, The Netherlands. ${ }^{7}$ Dept of Respiratory Medicine, Medical School of Alexandroupolis, Democritus University of Thrace, Alexandroupolis, Greece. ${ }^{8} \mathrm{Clinic}$ for Thoracic Surgery, Clinical Center of Serbia, Belgrade, Serbia. ${ }^{9}$ Dept of Thoracic Oncology, Pleural Diseases and Interventional Pulmonology, Hospital North Aix-Marseille University, Marseille, France. ${ }^{10}$ Dept of Cardiothoracic Surgery, Odense University Hospital, Odense, Denmark. ${ }^{11}$ Pulmonary and Thoracic Oncology Dept, Hospital of the University (CHU) of Lille, Lille, France. ${ }^{12}$ Oxford Centre for Respiratory Medicine, University Hospitals, NHS Foundation Trust, Oxford, UK. ${ }^{13}$ Dept of Thoracic Surgery, Carlo Forlanini Hospital, Azienda Ospedaliera San Camillo Forlanini, Rome, Italy. ${ }^{14}$ Task force chairperson.
\end{abstract}

Correspondence: Anna C. Bibby, Academic Respiratory Unit, University of Bristol Medical School Translational Health Sciences, 2nd Floor L\&R Building, Southmead Hospital, Bristol BS10 5NB, UK.

E-mail: Anna.Bibbylabristol.ac.uk

@ERSpublications

Management options for malignant pleural effusions have advanced over the past decade, with highquality randomised trial evidence informing practice in many areas. However, uncertainties remain and further research is required http://ow.ly/rNt730jOxOS

Cite this article as: Bibby AC, Dorn P, Psallidas I, et al. ERS/EACTS statement on the management of malignant pleural effusions. Eur Respir J 2018; 52: 1800349 [https://doi.org/10.1183/13993003.00349-2018].

ABSTRACT Malignant pleural effusions (MPE) are a common pathology, treated by respiratory physicians and thoracic surgeons alike. In recent years, several well-designed randomised clinical trials have been published that have changed the landscape of MPE management. The European Respiratory Society (ERS) and the European Association for Cardio-Thoracic Surgery (EACTS) established a multidisciplinary collaboration of clinicians with expertise in the management of MPE with the aim of producing a comprehensive review of the scientific literature.

Six areas of interest were identified, including the optimum management of symptomatic MPE, management of trapped lung in MPE, management of loculated MPE, prognostic factors in MPE, whether there is a role for oncological therapies prior to intervention for MPE and whether a histological diagnosis is always required in MPE.

The literature revealed that talc pleurodesis and indwelling pleural catheters effectively manage the symptoms of MPE. There was limited evidence regarding the management of trapped lung or loculated MPE. The LENT score was identified as a validated tool for predicting survival in MPE, with Brims' prognostic score demonstrating utility in mesothelioma prognostication. There was no evidence to support the use of oncological therapies as an alternative to MPE drainage, and the literature supported the use of tissue biopsy as the gold standard for diagnosis and treatment planning.

The article has been co-published with permission in the European Respiratory Journal and the European Journal of Cardio-Thoracic Surgery. All rights reserved in respect of European Respiratory Journal, ๑ European Respiratory Society 2018 and European Journal of Cardio-Thoracic Surgery, (c) European Association for Cardio-Thoracic Surgery 2018. The articles are identical except for minor stylistic and spelling differences in keeping with each journal's style. Either citation can be used when citing this article. 


\section{Introduction}

Malignant pleural effusions (MPE) are common, affecting up to $15 \%$ of all patients with cancer [1]. The incidence of MPE is likely to rise as global cancer incidence increases and overall survival improves. The majority of patients with MPE are symptomatic, with breathlessness the most common symptom [2]. The presence of MPE usually represents advanced or metastatic disease, and consequently survival is poor, ranging from a median of 3 months to 12 months depending on underlying patient and tumour factors [2]. The focus of treatment is inevitably palliative, and aimed at relieving symptoms.

Existing guidelines regarding the management of MPE were published over 7 years ago [2]. A number of high-quality trials have been published subsequently, many of which have changed practice [3-5]. Additionally, as increasing numbers of pleural interventions are being undertaken and experience with different management approaches has grown, new hurdles and issues have become apparent. This statement was written to summarise the evidence with regard to management of MPE in general, and in relation to specific questions that may be encountered by clinicians who manage MPE.

\section{Methods}

The task force was assembled at the European Respiratory Society (ERS) Annual Congress in London 2016 with the goal of producing an expert statement on the management of MPE. The task force was created based on the recommendations of the ERS Scientific Committee and the European Association for Cardio-Thoracic Surgery (EACTS) Guidelines Committee and included nine respiratory physicians and five thoracic surgeons from nine different European countries (supplementary material: Appendix A). The aim of the task force was to develop a statement that represented a comprehensive, expert scientific review of the literature, identified by systematic searches with conclusions supported by accompanying references.

Topics to be covered by the statement were decided at the initial meeting of the task force. Six clinical questions were chosen to be covered by the statement. They comprised the optimum management of 1) symptomatic MPE, 2) MPE with trapped lung and 3) loculated MPE; 4) factors predicting prognosis; 5) whether oncological therapy should precede definitive fluid management in treatment-sensitive tumours; and 6) whether histological diagnosis is always required. Certain topics have been covered in previous guidelines and statements (i.e. questions 1, 3 and 4), and the intention of the task force was to present an updated summary of the literature, whilst other topics have not been specifically reviewed before (i.e. questions 2, 5 and 6). Each question, except the question on prognosis, was structured using the PICO (Patients, Intervention, Comparison and Outcomes) format. The PICO criteria for each question are presented in supplementary material: Appendix B.

The literature search was undertaken in January 2017 by an Information Scientist at the University of York, with guidance from a task force member (ACB). Three medical databases, Medline/PUBMED (National Library of Medicine, USA), EMBASE (Elsevier, the Netherlands) and Cochrane Library (UK), were searched using a combination of $\mathrm{MeSH}$ headings and keywords appropriate to the clinical question. Search results were limited to papers in English relating to adult patients. The full search strategy for each clinical question is shown in supplementary material: Appendix C. Once the search had been run, further potentially eligible articles were identified by snowballing, including reviewing the reference lists of identified papers. The search was repeated in January 2018 to identify recently published papers.

Abstracts were screened for inclusion by two task force members (ACB and NAM). Articles were included or excluded based on pre-specified eligibility criteria for each clinical question (supplementary material: Appendix D). Each reviewer screened abstracts independently before results were compared. Any disagreements were resolved by discussion, with involvement from the task force chairs if necessary.

Six subgroups were formed, with each comprising a combination of physicians and surgeons with a range of expertise. Each subgroup reviewed the full-text articles of the reference material and further excluded any articles that did not match the eligibility criteria. The Preferred Reporting Items for Systematic Reviews and Meta- Analyses (PRISMA) diagram for each clinical question is shown in supplementary material: Appendix E.

Subgroups prepared drafts summarising the relevant literature for their clinical question. These drafts were reviewed by the task force at a meeting during the 2017 ERS congress in Milan. Comments and suggestions were made, after which subgroups revised their drafts and submitted them to the writing

This article has supplementary material available from erj.ersjournals.com

Received: Feb 182018 | Accepted after revision: March 282018

This article was endorsed by the ERS Science Council and Executive Committee in April 2018, and by the European Association for Cardio-Thoracic Surgery in March 2018. 
committee (ACB, NAM). The writing committee collated the drafts into a complete statement that was circulated to all task force members. Feedback was incorporated into a revised second draft that was disseminated to the task force. Further revisions were discussed at a teleconference in November 2017, leading to production of the final draft. This was reviewed and approved by all members; hence, the final document represents a consensus statement of the entire task force.

The statement describes current practice regarding the management of MPEs, and summarises the evidence as it currently stands. The statement does not make recommendations for clinical practice. It has been endorsed by the ERS Scientific Committee and the EACTS Guideline Committee and peer-reviewed by expert reviewers on behalf of the European Respiratory Journal and the European Journal of Cardio-Thoracic Surgery.

\section{Question 1: what is the best definitive treatment for patients with symptomatic malignant pleural effusions?}

MPE are usually associated with significant symptoms. Because the majority of patients with MPE will experience fluid re-accumulation after therapeutic aspiration, a definitive pleural intervention is recommended [2]. For the purposes of this document, "definitive" is regarded as a procedure intended to provide long-term relief from pleural effusion symptoms. Serial thoracentesis is not considered definitive and is therefore not included.

The literature covers many definitive pleural interventions for MPE, including pleurodesis using a chemical agent (e.g. tetracycline, doxycycline and bleomycin), talc pleurodesis via thoracoscopy (poudrage) or chest tube (slurry), mechanical pleurodesis at surgery, pleurectomy, and insertion of indwelling pleural catheters (IPC). This document will review the available evidence for the more common interventions.

\section{Chemical pleurodesis}

Three systematic reviews assessed the efficacy of different pleurodesis agents. BuCKNOR et al. [6] conducted a best-evidence review of silver nitrate as a pleurodesis agent, in which 42 papers were identified and eight included. Half of these papers related to animal studies or non-malignant populations, but for the four studies undertaken in MPE, silver nitrate pleurodesis rates of $89-96 \%$ were reported. This compared favourably with pleurodesis rates of $84 \%$ with talc slurry in the only randomised trial included in the review [7]. Further support for silver nitrate was provided by a small case series of 17 patients in whom talc pleurodesis failed; $89 \%$ of these patients subsequently achieved pleurodesis with silver nitrate [8].

TAN et al. [9] conducted a systematic review and meta-analysis of randomised trials and included 46 studies with a total of 2053 patients. Pleural fluid recurred less frequently with talc (poudrage or slurry) compared with doxycycline or bleomycin. In the most recent and most thorough assessment in the literature, CLIVE et al. [1] conducted a network meta-analysis of MPE pleurodesis strategies. Talc poudrage was ranked highest in terms of fluid control, with clear benefit compared with bleomycin and tetracycline. Side effects were similar across the agents studied, although large-particle (graded) talc was recommended over mixed-particle size to reduce the risk of acute respiratory distress syndrome (ARDS). The authors noted a high or unclear risk of bias in all included studies, as well as high heterogeneity between trials. There was a lack of patient-reported outcomes and further work is required in this area to allow clinicians to understand patients' preferences and formulate individualised management plans.

\section{Talc poudrage versus talc slurry}

Three systematic reviews addressed thoracoscopic talc poudrage (via surgical video-assisted thoracoscopic surgery (VATS) or medical thoracoscopy) versus bedside talc slurry. TAN et al. [9] demonstrated that poudrage was associated with less recurrence than slurry (relative risk $0.21,95 \%$ CI $0.05-0.93$ ) based on two studies. In a network meta-analysis, talc poudrage was ranked higher than slurry in terms of fluid control, accepting bias in the included studies [1]. Mummadi et al. [10] conducted a systematic review and meta-analysis of talc poudrage versus slurry. Of 28 studies identified, four were included as high quality. No overall difference in successful pleurodesis was found (relative risk 1.06, 95\% CI 0.99-1.14), but poudrage was associated with a higher risk of respiratory complications (relative risk 1.91, 95\% CI 1.24-2.93). The increased complication rate was driven entirely by a single study by DRESLER et al. [11], the largest in the literature. In that trial, 501 patients were randomised to talc poudrage or slurry (250 versus 251 patients) using non-graded talc. The primary outcome was radiographic absence of effusion at 30 days in those who survived and in whom initial lung expansion was $>90 \%$. There was no difference overall (78\% versus $71 \%$ ), but in a post hoc subgroup analysis of breast and lung cancer patients, poudrage appeared superior ( $82 \%$ versus $67 \%$ ). There was an excess of adverse events in the talc poudrage group 
( $14 \%$ versus $6 \%$ for respiratory complications, and $8 \%$ versus $4 \%$ for respiratory failure), including 11 deaths.

YIM et al. [12] randomised 57 MPE patients with expandable lungs to talc poudrage or slurry, showing no difference in any outcome including complications. Similarly, TerRA et al. [13] randomised 60 patients to talc poudrage or slurry, and demonstrated no difference in outcome, although a greater proportion of poudrage patients demonstrated complete lung expansion.

Four non-randomised studies compared talc poudrage to slurry. Two studies totalling 277 patients demonstrated no difference in pleurodesis outcomes $[14,15]$, whereas two others totalling 257 patients demonstrated higher pleurodesis success rates, shorter tube duration ( 9 days versus 6 days) and longer effusion-free survival with poudrage $[16,17]$.

There were 17 case series of $>100$ patients reporting the utility of talc poudrage in the literature, comprising 6347 patients. Varying doses of talc were used and definitions of pleurodesis success and complications differed. Success rates ranged from $77 \%$ to $98 \%$, and complications from $2 \%$ to $17.2 \%$, including mortality in some studies [18-34]. Important specific results in these studies included no incidences of ARDS in 558 patients undergoing talc poudrage with graded talc [22], lower pleurodesis success in patients with pleural $\mathrm{pH}<7.2$ [31], and improved dyspnoea but deteriorating overall quality of life post-pleurodesis in MPE [32].

\section{Chest tube size}

The majority of studies that demonstrated high pleurodesis rates with talc used large bore chest tubes $(\geqslant 24 \mathrm{~F})$. Numerous case series suggest reasonable pleurodesis rates using smaller bore catheters with a number of different agents.

Two randomised trials directly addressed chest tube size in pleurodesis. CLEMENTSEN et al. [35] randomised 18 patients to small bore catheter $(10 \mathrm{~F})$ or large bore tube $(24 \mathrm{~F})$ for tetracycline pleurodesis, and found no significant difference in pleurodesis rates. Although this was taken to indicate there was no difference in pleurodesis rates according to chest tube size in MPE, the study was underpowered for this outcome and was not designed as a non-inferiority trial. RAHMAN et al. [4] conducted a $2 \times 2$ factorial randomised trial assessing opiate versus nonsteroidal anti-inflammatory drugs and small (12F) versus large (24F) chest tubes in 320 patients with MPE undergoing talc pleurodesis. Pain comparisons were powered for superiority and pleurodesis for non-inferiority. Small bore tubes failed to meet the non-inferiority margin of $15 \%$, demonstrating lower pleurodesis success (30\% versus $24 \%$ pleurodesis failure).

\section{Other issues regarding talc pleurodesis}

In the past, it has been assumed that adequate distribution of talc throughout the thoracic cavity was required to achieve successful pleurodesis. MAGER et al. [36] randomised 20 patients to either rotation or bed rest in the supine position following administration of radiolabelled talc. No difference in distribution was found between the two arms, and thus rotation does not increase the likelihood of pleurodesis success.

Pleurodesis is a highly painful procedure in some patients, and most physicians use opiate analgesia for the procedure. Although nonsteroidal anti-inflammatory drugs are effective analgesics for acute pain, they have historically been avoided during pleurodesis owing to fears that their anti-inflammatory effect may reduce pleurodesis success. RAHMAN et al. [4] randomised 320 patients to high-dose ibuprofen (800 mg three times daily) or opiate during pleurodesis for MPE and demonstrated no significant difference in pleurodesis success or pain using a non-inferiority design. These results suggest nonsteroidal drugs need not be avoided in patients undergoing pleurodesis for MPE.

Small-particle (or ungraded) talc is thought to be associated with significantly more side effects than large-particle (graded) talc, including ARDS and respiratory failure [11, 22]. Small-particle talc was associated with higher inflammatory cytokine responses in one small non-randomised comparative study [37]. Interestingly, higher inflammatory responses were seen in patients following talc poudrage with successful pleurodesis compared with non-successful pleurodesis in a case series [38]. Similarly, higher fibrinolytic activity in pleural fluid has been associated with pleurodesis failure [39].

Whilst pleurodesis aims to palliate symptoms rather than extend survival, one retrospective non-randomised study found talc poudrage pleurodesis was associated with longer survival compared with repeated thoracentesis [40]. However, the authors conflated correlation with causality, and ignored potential confounding by indication in the two treatment arms. Another series of 91 patients explored factors associated with poor survival after talc poudrage [41]. Poor performance status and prior use of 
chemo/radiotherapy were adverse prognostic factors, and these clinical parameters may be helpful in triaging patients to treatments.

\section{Surgical options}

Surgical options for MPE (aside from VATS talc poudrage which is covered in the section above) include pleurectomy and abrasion pleurodesis. Several cases series suggest partial and total pleurectomy are effective treatments for MPE [42-44].

Four randomised trials have compared surgical techniques with "medical" pleurodesis. CRNJAC et al. [45] randomised breast cancer MPE patients to thoracoscopic abrasion or bedside talc slurry ( $5 \mathrm{~g})$ and analysed radiological outcomes stratified by pleural $\mathrm{pH}$ levels. Pleurodesis success rates were not significantly different between effusions with $\mathrm{pH}>7.3$ and with $\mathrm{pH}<7.3$ (92\% versus $91 \%$ ). Hospital stay was shorter in the surgical group ( 5.5 days versus 7.5 days, $\mathrm{p}<0.05$ ), and complication rate and mortality also favoured abrasion ( $16 \%$ versus $26 \%$ and $0 \%$ versus $9.5 \%$, respectively). A smaller randomised trial compared the same interventions, using surrogate inflammatory outcomes. Surgical pleurodesis was associated with a greater increase in inflammatory cytokines (although nonsignificant) and better patient-reported outcomes [46].

Gu and WANG [47] randomised 53 non-small cell lung cancer (NSCLC) MPE patients to VATS pleurectomy or chest tube drainage, although it is unclear whether a pleurodesis agent was given in the chest drain arm. A significant improvement favouring VATS was seen in MPE response rates $(92.3 \%$ versus $59.3 \%, \mathrm{p}<0.05$ ) and Karnofsky performance status (mean $33.5 \pm 11.3$ and $24.07 \pm 10.5, \mathrm{p}<0.05$ ), but there were no differences in overall survival.

In the largest randomised trial of its type, RinToul et al. [5] compared fluid control rates in 196 mesothelioma patients randomised to VATS pleurectomy or talc pleurodesis using poudrage or slurry. There was no significant difference in pleurodesis, and VATS was associated with higher expense and increased adverse events.

A non-randomised comparison of talc pleurodesis, abrasion and pleurectomy for MPE demonstrated longer hospital stays and worse mortality and morbidity following surgery [48]. Similarly, in another study, pleurodesis rates were lower in patients who underwent local anaesthetic thoracoscopy compared with VATS, but post-operative drainage, mortality, morbidity and costs were also lower in the medical thoracoscopy group [49]. Greater improvements in early physical health, global health and dyspnoea were seen with medical thoracoscopy, although this group comprised historic controls and was therefore at risk of selection bias.

\section{Indwelling pleural catheters}

IPCs are an alternative to pleurodesis that offer long-term symptom control via regular home drainage of fluid. Multiple case series, totalling 1533 patients, have reported their utility in MPE management, specifically in terms of improving breathlessness and other symptoms, and quality of life [50-55]. A systematic review of 19 case series, totalling 1370 patients treated with IPC, reported symptomatic improvement in $96 \%$, with removal owing to complications required in $8.5 \%$ [56].

There are four randomised controlled trials comparing IPCs with chemical pleurodesis [3, 57-59]. PUTNAM et al. [57] randomised $144 \mathrm{MPE}$ patients to IPC or doxycycline pleurodesis in a 2:1 ratio, demonstrating comparable improvement in symptoms in both groups. However, the IPC group spent less time in hospital ( 1 day versus 6.5 days), and had a $46 \%$ pleurodesis rate at 27 days.

In the TIME2 trial, DAVIES et al. [3] randomised patients to IPC or inpatient talc slurry pleurodesis via a $12 \mathrm{~F}$ intercostal drain, with a primary outcome measure of patient-reported breathlessness over 6 weeks.

No significant difference in dyspnoea scores was found between the groups, with a small difference in breathlessness favouring IPC at 6 months. IPCs were associated with reduced time in hospital (0 versus 4 days) and reduced requirement for further procedures (6\% versus $22 \%$ ), but also with increased adverse events (OR 4.70, 95\% CI 1.75-12.60, $\mathrm{p}=0.002$ ).

More recently, the AMPLE study randomised 146 patients with MPE to IPC insertion or talc slurry pleurodesis via a chest drain [58]. Patients who received an IPC had shorter hospital stays (10 versus 12 days, $\mathrm{p}=0.03$ ) and required fewer subsequent pleural interventions ( 3 versus $16, \mathrm{p}=0.001$ ) than the pleurodesis group. Both arms reported sustained improvements in breathlessness and quality of life scores, with no difference between the two arms. Complication rates were higher in the IPC group (30\% versus $18 \%)$, but there was only one serious adverse event compared with three in the chest tube arm.

Dеммy et al. [59] randomised 57 patients to IPC placement with daily drainage or bedside talc pleurodesis, with a composite primary outcome of "success" based on reliable drainage, pleurodesis and 30-day survival. The recruitment target was not met, and a secondary endpoint of survival with effusion 
control was added retrospectively. IPCs were more successful for the primary outcome (62\% versus $46 \%$, $\mathrm{p}=0.064)$ and secondary outcome ( $82 \%$ versus $52 \%, \mathrm{p}=0.024)$. However, the results of this study should be interpreted with caution given the failure to recruit the target sample size, the potential bias introduced by adding outcomes post hoc, and the limited clinical applicability of the primary outcome.

Three non-randomised studies compared IPCs with poudrage [60], talc slurry [61] and VATS pleurodesis or decortication [62]. These studies reported reduced hospital stay and fewer repeat procedures for IPCs compared with slurry or poudrage [60,61], but reduced survival compared with decortication [62]. However, all suffer from potential selection bias. One study assessed patient-reported outcome measures in MPE interventions, including patients having IPC, talc slurry pleurodesis and surgical VATS [63]. All patients demonstrated improved functional assessment and breathlessness scores, with no statistically significant difference between treatment groups.

Regarding IPC drainage regimens, the multi-centre, randomised ASAP trial [64] revealed that daily IPC drainage was more likely to result in auto-pleurodesis, either complete or partial, within 12 weeks compared with alternate day drainage (pleurodesis rate $47 \%$ versus $24 \%, \mathrm{p}=0.003$ ). Adverse event rates (and specifically infection rates) were similar in the two arms and although almost $30 \%$ of the 149 patients randomised died before the 12 -week primary endpoint, deaths were evenly distributed between the two treatment regimens. Importantly, patients with trapped lung were excluded from the study, a pertinent consideration when applying this result to clinical care because aggressive drainage is likely to cause significant pain in this population. Careful evaluation of individual patients is therefore required before a daily drainage approach is followed.

\section{Combined procedures}

Given the growing evidence supporting IPCs, there is increasing interest in combining their use with other pleurodesis procedures. Three case series totalling 148 patients reported the use of IPCs during VATS [65] and combined with talc poudrage pleurodesis [66,67]. The combination of poudrage and IPC was associated with short hospital stays (1-3 days) and removal of catheters after successful pleurodesis within $\sim 7$ days. A single non-randomised study used propensity matching to compare VATS poudrage with IPC placement at VATS in 60 patients [68]. The IPC group had shorter hospital stays and lower morbidity.

There is a lack of high-quality randomised evidence for the use of combined procedures in MPE, but this is a potential treatment direction for the future.

\section{In summary}

Talc is the most effective agent for chemical pleurodesis in MPE, and graded-particle talc appears safe. The data suggest that thoracoscopic talc poudrage (via surgical VATS or medical thoracoscopy) may be slightly more effective than slurry for MPE pleurodesis, and an ongoing randomised trial in the UK is aiming to answer this question [69]. Surgical pleurodesis procedures are no more effective than talc, especially in mesothelioma where evidence from a randomised controlled trial shows that VATS pleurectomy is associated with more complications and longer hospital stays, but no additional benefit in terms of pleurodesis success [70].

Large bore tubes (e.g. 24F) are associated with higher pleurodesis success rates in talc pleurodesis than smaller drains (e.g. 12F), with nonsteroidal drugs as an effective analgesia option that does not lower pleurodesis rates. IPCs appear to be as effective at relieving MPE symptoms as talc pleurodesis and are associated with reduced time in hospital, although adverse event rates appear to be higher than for talc.

\section{Question 2: what is the optimal management for malignant pleural effusion with trapped lung?}

Trapped lung describes the situation in which the lung is unable to fully expand to fill the hemithorax, rendering the parietal and visceral pleura either partly or completely unopposed. Trapped lung can occur as a result of pleural thickening causing encasement of the lung, proximal endobronchial obstruction causing distal lung collapse or chronic atelectasis. Some authors differentiate between "lung entrapment", in which an active pleural process such as malignancy causes a visceral pleural peel to form, thus preventing lung expansion, and "trapped lung", in which the fibrous peel has arisen as a consequence of remote inflammation in the pleural space that is no longer active [71, 72]. For the purpose of this document, the term "trapped lung" will be used to cover both clinical entities.

Whether trapped lung can be predicted is an issue beyond the scope of this document. Pleural manometry, M-mode ultrasonography and patients' symptoms during aspiration have all been proposed as methods of predicting trapped lung [71, 73-78]. However, as yet none have been proven prospectively and further evidence is required before they can be adopted into routine clinical practice. 
Regarding the management of trapped lung in MPE, there is little high-quality evidence. The literature is complicated by certain issues, including different definitions of the disease and the potential for variation in the degree of lung entrapment between individual patients and studies. In addition, several studies include patients with trapped lung, loculated effusions or previous failed pleurodesis, but do not clearly differentiate between patient groups when reporting outcomes. There are no randomised controlled trials specifically investigating trapped lung, and consequently the evidence must be interpreted with awareness of the risk of selection bias (in non-comparative studies) and confounding by indication (in non-randomised comparative studies). Furthermore, it is highly likely that institutional preference and expertise will determine the choice of intervention for trapped lung, introducing additional bias.

A single systematic review focusing on the optimal approach to MPE concluded that IPCs are indicated in trapped lung [79]. This conclusion was based on two studies out of 14 included in the review. The first, by PIEN et al. [80], was a retrospective review of 11 patients with trapped lung who underwent IPC insertion and home drainage. All but one patient described symptomatic benefit, and 12 out of 13 catheters placed remained in situ until the patient died. Serious adverse events, i.e. empyema, IPC blockage and catheter fracture, occurred in three patients.

Additional information regarding IPC in trapped lung is available from the randomised trial of DEMMY et al. [59] of talc pleurodesis versus IPCs in MPE. The subgroup of nine patients with trapped lung had higher effusion control rates at 30 days in the IPC arm compared with the talc pleurodesis arm, and better dyspnoea-free exercise scores ( 7.8 versus $4.5, \mathrm{p}=0.02$ ).

A non-randomised comparative study compared the use of poudrage pleurodesis at VATS to IPCs, with the intervention chosen according to whether trapped lung was present, suggesting successful treatment in trapped lung with IPCs [81].

There are several observational studies reporting the value of IPC in MPE with trapped lung, the results of which are summarised in table 1. It is worth noting that symptomatic outcomes were inconsistently defined across these studies, and whilst some studies reported the number of patients who experienced symptomatic relief, others subjectively graded the size of the response in individuals. Nonetheless, IPCs appear effective in trapped lung, with symptomatic improvement reported in $>94 \%$ of patients in five studies totalling 133 patients [51, 80, 82-84], although a single study of 48 patients reported lower symptom relief rates of $48 \%$ [85]. Three of these studies included patients who had undergone VATS and been diagnosed with trapped lung intra-operatively, and so received an IPC at the end of the procedure $[55,82,85]$. In these studies, it is impossible to determine which procedure was responsible for which outcomes, both in terms of symptomatic benefit and adverse events, which were numerous. Length of stay was consistently shorter for trapped lung patients treated with IPCs than for comparator groups (usually comprising patients with non-trapped lung undergoing VATS talc poudrage) [81, 82].

Other approaches to managing malignant trapped lung include surgical decortication and intra-pleural fibrinolytic therapy. Pleuroperitoneal shunts have historically been used in trapped lung; however, the supporting evidence is of poor quality, complications rates are high and they are not currently used in routine clinical practice $[34,86,87$ ]. From a surgical perspective, YIM et al. [88] reported "good outcomes" in seven patients with trapped lung who underwent VATS decortication. A randomised controlled trial is underway in the UK assessing the role of surgical pleurectomy/decortication versus IPC in patients with mesothelioma and trapped lung (Meso-TRAP).

Hsu et al. [89] investigated the use of 100000 IU urokinase via IPCs in surgically inoperable patients with trapped lung or loculated effusions. Three out of 12 patients with trapped lung demonstrated "excellent" radiographic improvement following treatment, which persisted until death in two out of the three. No adverse events were reported. However, the relevance of radiographic resolution, specifically its inconsistent relationship with symptoms, makes this finding difficult to interpret in a clinical context.

\section{In summary}

There is a lack of good-quality published evidence but IPCs appear to be an effective option in the management of MPE trapped lung. Dedicated prospective trials are needed to fully evaluate the utility of IPCs in trapped lung, and also to evaluate surgical interventions and the role of fibrinolytic therapy.

\section{Question 3: how should septated and loculated malignant pleural effusion be} managed?

Loculated MPE are defined as MPE with multiple loci, i.e. there is more than one fluid collection, or the effusion is divided into multiple separate pockets of fluid. This is different to septated effusions, in which fibrinous strands have formed within an effusion, usually as a result of excessive fibrin formation due to inflammatory-mediated changes in procoagulant and fibrinolytic activity [90]. Septated effusions can 
TABLE 1 Summary of observational studies that used IPCs for trapped lung

\begin{tabular}{|c|c|c|c|c|c|c|c|c|c|}
\hline Author & $\begin{array}{c}\text { Year of } \\
\text { publication }\end{array}$ & $\begin{array}{c}\text { Total } \\
\text { subjects }\end{array}$ & $\begin{array}{l}\text { Subjects } \\
\text { with } \\
\text { trapped } \\
\text { lung }\end{array}$ & $\begin{array}{c}\text { Subjects } \\
\text { reporting } \\
\text { symptomatic } \\
\text { improvement } \\
\%\end{array}$ & $\begin{array}{l}\text { Time } \\
\text { IPC in } \\
\text { situ } \\
\text { days }\end{array}$ & $\begin{array}{l}\text { Median } \\
\text { survival } \\
\text { days }\end{array}$ & $\begin{array}{l}\text { Pleurodesis } \\
\text { rate } \%\end{array}$ & Complications & Other outcomes/comments \\
\hline WARREN [51] & 2008 & 231 & 28 & 100 & 43.3 & NR & 54 & $\begin{array}{l}\text { Infection (mainly } \\
\quad \text { cellulitis) } 5 \\
\text { Catheter blockage } 11 \\
\text { Skin reaction to } \\
\text { dressing } 1\end{array}$ & $\begin{array}{l}\text { Combined results for all } \\
\text { patients undergoing IPC } \\
\text { insertion }\end{array}$ \\
\hline BAZERBASHI [55] & 2009 & 125 & NR & NR & 87 & 84.1 & 76 & $\begin{array}{l}\text { Wound infection } 7 \\
\text { Peri-catheter leak } 2 \\
\text { Catheter blockage } 2 \\
\text { Catheter displacement } 2 \\
\text { Tumour seeding } 1\end{array}$ & $\begin{array}{l}\text { Combined results for patients } \\
\text { with trapped lung and } \\
\text { previous failed pleurodesis }\end{array}$ \\
\hline Онм [81] & 2003 & 41 & 34 & NR & NR & NR & NR & NR & Length of stay $<2$ days in $56 \%$ \\
\hline Pien [80] & 2001 & 11 & 11 & 100 & 115 & NR & NR & $\begin{array}{l}\text { Cellulitis } 2 \\
\text { Pleural infection } 2 \\
\text { Catheter occlusion } 1\end{array}$ & \\
\hline QURESHI [82] & 2008 & 127 & 52 & 94.2 & 93.8 & 126 & 42.3 & $\begin{array}{l}\text { Surgical emphysema } 2 \\
\text { Catheter blockage } 2 \\
\text { Cellulitis } 2 \\
\text { Fluid loculation } 2\end{array}$ & \\
\hline VAN DEN TOORN [83] & 2005 & 17 & 17 & 100 & 63 & NR & NR & $\begin{array}{l}\text { Pleural Infection } 1 \\
\text { Cellulitis } 1 \\
\text { Catheter displacement } 3 \\
\text { Hyponatraemia } 1\end{array}$ & \\
\hline EFтнуміоu [85] & 2009 & 48 & 48 & 48 & NR & NR & NR & $\begin{array}{l}\text { Peri-catheter } \\
\quad \text { leakage } 13 \% \\
\text { Occlusion } 4 \% \\
\text { Catheter displacement } 4 \%\end{array}$ & $\begin{array}{l}65 \% \text { moderately or very } \\
\text { satisfied with mobility } \\
\text { improvement }\end{array}$ \\
\hline SIORIS [91] & 2009 & 51 & NR & NR & 120 & 91 & 21 & $\begin{array}{l}\text { Early complications } 4 \\
\text { Pleural infection } 3 \\
\text { Catheter displacement } 1 \\
\text { Catheter blockage } 2 \\
\text { Cellulitis } 1\end{array}$ & $\begin{array}{l}\text { Combined results for patients } \\
\text { with trapped lung, patients } \\
\text { with high volume effusions } \\
\text { and patients unsuitable for } \\
\text { general anaesthetic }\end{array}$ \\
\hline BURGERS [84] & 2006 & 25 & NR & 100 & NR & 70 & 24 & $\begin{array}{l}\text { Empyema } 3 \\
\text { Haemoptysis } 1\end{array}$ & \\
\hline
\end{tabular}


become loculated over time, but the presence of septations in MPE does not necessarily prevent the free flow of fluid within an effusion. In contrast, loculation can prevent complete drainage of the pleural space and limit lung re-expansion, potentially contraindicating pleurodesis or resulting in insufficient symptomatic relief in patients with IPCs.

Septations are common in MPE. One retrospective analysis of 540 consecutive patients who underwent medical thoracoscopy for MPE found that 332 (60\%) had some degree of adhesion (i.e. septation), which obstructed two thirds or more of the thoracoscopic view in 84 (15\%) [92]. The extent of pleural adhesions correlated with a greater pleural tumour burden and shorter median survival [92]. Transthoracic ultrasonography (TUS) outperforms computed tomography (CT) in the identification of septations. In a prospective study of 64 patients undergoing VATS, pre-operative CT had $71 \%$ sensitivity and $72 \%$ specificity for detecting septations [93]. In contrast, two series of 142 and 117 patients reported sensitivities of $81 \%$ and $88 \%$, respectively, and specificities of $96 \%$ and $83 \%$, for TUS identification of septations prior to thoracic surgery $[94,95]$. Another small observational study further supported the use of TUS over CT as an effective method for identifying thick pleural septations prior to thoracoscopy (sensitivities $100 \%$ and $12.5 \%$ respectively) [96].

TUS has a role in treating loculated effusions, and has been shown to reduce complications and increase yield when used to guide interventions in loculated collections [97, 98]. However, the utility of TUS is limited in the presence of mediastinal loculations or loculations involving the fissures, because the overlying lung prevents imaging of the fluid beneath it. In these situations, CT is of greater value, with a high sensitivity for identifying loculations $[98,99]$.

Septations can be broken up under direct vision at thoracoscopy (medical or surgical), whilst thoracic surgery is usually required to access multiple loculations, especially those positioned on the mediastinum. Multiple drains have been used to drain loculated effusions in the setting of pleural infection [100, 101]; however, multiple procedures are not ideal in patients with MPE. Additionally, if the underlying lung is non-expandable, pleurodesis will be ineffective and this approach will not result in definitive fluid control.

Intra-pleural fibrinolytic agents have been shown to improve fluid drainage in loculated pleural infection [102], and uncontrolled small case series have reported their use in symptomatic loculated MPE with incomplete initial drainage [103-110]. Intra-pleural fibrinolytic agents increased fluid drainage in all cases, and improved symptoms and radiological appearances in 60\% [110], 86\% [109] and, in most studies, $100 \%$ of patients [103-108]. Different drugs, including streptokinase [103-107, 110], urokinase [109] and tissue plasminogen activator [108, 110], were employed at varying dosages.

Four controlled studies, three of which were randomised, investigated the role of intra-pleural fibrinolysis for the treatment of loculated MPE [89, 111-113]. The first, which used a historical control group, prospectively evaluated 36 patients with symptomatic loculated MPE after drainage with an $8 \mathrm{~F}$ catheter who were unsuitable for surgery [89]. The administration of intra-pleural urokinase (100000 IU daily for 3 days) resulted in a greater than two-third reduction in radiological effusion size in 26 patients $(72.2 \%)$. All 26 subsequently received minocycline pleurodesis, with lifelong fluid control in 21 (80.8\%). Radiological lung expansion was significantly greater than in 40 retrospectively analysed historical controls with loculated MPE who did not receive fibrinolytic agents.

The second study randomised 47 patients with symptomatic MPE to receive intra-pleural streptokinase (250000 IU twice daily for three doses) or pleural drainage only [111]. No information was provided regarding the existence of pleural adhesions. In the fibrinolytic group, $96 \%$ of patients achieved radiological lung expansion and were subsequently able to receive talc slurry, compared with $75 \%$ in the control group ( $\mathrm{p}=0.035)$. However, pleurodesis success at 1 month was similar in both groups $(74 \%$ versus $56 \%, \mathrm{p}=0.28)$.

The third study randomly allocated 40 patients with loculated MPE on CT to receive intra-pleural streptokinase (four separate doses of $250000 \mathrm{U}$ ) or placebo (saline) administered through a $20 \mathrm{~F}$ tube, after which talc slurry pleurodesis was performed [112]. The fibrinolytic group had higher daily drainage volumes at all time points $(\mathrm{p}<0.001)$, with a greater proportion of patients showing CT improvements of $>40 \%$ ( $85 \%$ versus $35 \%, p=0.001)$. Fibrinolytic therapy was also associated with reduced requirements for supplementary oxygen $(10 \%$ versus $45 \%)$ and lower rates of pleurodesis failure at 1 month (11\% versus $45 \%)$, although only the first result reached statistical significance.

Finally, in the TIME3 trial, 71 patients with non-draining MPE due to fibrinous adhesions received either urokinase $(100000 \mathrm{U}$, three doses over $36 \mathrm{~h}$ ) or placebo, followed by talc slurry pleurodesis after $24 \mathrm{~h}$ [113]. There was no difference in dyspnoea scores on a visual analogue scale over the first month or pleurodesis failure rates at 1 year between the fibrinolysis and placebo groups. However, urokinase performed better than placebo for secondary outcome measures, including an $18 \%$ greater reduction in pleural opacity on 
chest radiography 2 days post-randomisation, shorter length of hospital stay (6.2 versus 8.7 days) and improved survival (48 versus 69 days; all $\mathrm{p}<0.05$ ). Notably, $48 \%$ of the study population died within 1 month of randomisation, highlighting the extremely poor prognosis of patients with this problem.

The use of fibrinolytic agents in patients with IPCs and loculated MPE has been studied in one multi-centre retrospective review [114]. A total of 66 patients (64 with an MPE) who developed symptomatic loculations with IPCs in situ were treated with intra-pleural fibrinolytic agents. Most patients received a single dose (range 1-6) of tissue plasminogen activator $(n=52)$, urokinase $(n=12)$ or streptokinase $(n=2)$. Following therapy, the volume of pleural fluid drained increased in $93.3 \%$ of patients and dyspnoea improved in $83 \%$. The area of pleural opacity on chest radiography decreased from $52 \%$ to $31 \%$ of the hemithorax in 13 evaluable patients. However, symptomatic loculations recurred in 27 patients (41\%) and only one of the 10 patients who received repeated fibrinolytic therapy had sustained improvement in drainage and symptoms.

\section{In summary}

Intra-pleural fibrinolytic agents increase the volume of fluid drainage and improve the radiological appearance in loculated MPE. However, they have no effect on clinical outcomes, such as dyspnoea or pleurodesis success. Alternatives, however, are limited for patients with loculated MPE for whom surgery is not suitable.

\section{Question 4: what factors predict prognosis in malignant pleural effusion?}

MPE management depends on prognosis. Patients with long survival require definitive interventions, whilst the aim for people with short life expectancy should be to maximise time at home [2].

Certain factors, i.e. tumour type, stage and performance status (PS), are accepted prognostic factors in malignancy, including MPE. In MPE, lung cancer carries the worst prognosis, whilst longer survival is seen in gynaecological tumours, predominantly due to the underlying tumour's sensitivity to treatment [2, 115-121]. Staging systems exist for each tumour that formally describe disease extent and prognosis [122]. Usually MPE signifies metastatic disease, higher stage and shorter survival, although mesothelioma is an exception to this rule $[122,123]$. Finally, PS is a global evaluation of function that predicts outcome in cancer, as well as being used as a tool to assess patients' suitability for oncological treatment [117, 118, 121, 124-129].

\section{Prognosticating in malignant pleural effusion}

Specific MPE-related prognostic factors include effusion size. Massive MPE, defined as fluid occupying the entire hemithorax, was associated with significantly worse survival in one large prospective study [130]. This finding was replicated in a subsequent retrospective study, although the definition of massive effusion differed [119].

Pleural fluid $\mathrm{pH}$ may also predict survival: an early study demonstrated worse prognosis in patients with pleural fluid $\mathrm{pH}<7.2$ [131]. However, whilst several subsequent studies replicated the original finding, albeit using lower $\mathrm{pH}$ cut-offs $[31,119,129]$, others found no relationship between $\mathrm{pH}$ and survival [41, 126]. Patient-level data from these studies were pooled in a meta-analysis that confirmed $\mathrm{pH} \leqslant 7.28$ was associated with shorter survival [116]. However, $\mathrm{pH}$ could not reliably predict 3-month survival and was therefore insufficiently accurate for clinical use. Pleural fluid glucose, which is closely related to $\mathrm{pH}$, was similarly non-predictive [31, 41, 119, 126, 129].

Other potentially prognostic pleural fluid variables include lactate dehydrogenase, which correlated with survival in multiple observational series $[119,129,131]$. Haemorrhagic fluid was also associated with reduced survival times in patients with lung cancer [119], and was a poor prognostic factor in patients with MPE undergoing thoracoscopy [132]. Positive pleural fluid cytology does not predict survival [118, 132], although detection of specific receptors or mutations, e.g. of epidermal growth factor receptor (EGFR), in fluid can have treatment and prognostic implications [133, 134]. Interestingly, high serum levels of vascular endothelial growth factor (VEGF) did not predict response to bevacizumab (a VEGF antagonist) in mesothelioma [135]. However, high serum and pleural fluid VEGF levels are associated with worse outcomes in MPE $[136,137]$, as are the downstream effects of inflammation, angiogenesis and tumour necrosis $[138,139]$.

Inflammation and cancer are closely related, and serum inflammatory markers can predict prognosis [140-143]. The Glasgow Prognostic Score combines C-reactive protein with serum albumin and has been validated to predict survival in several tumour types [144-146]. Another inflammation-based prognostic score is the serum neutrophil to lymphocyte ratio (NLR), for which high values reflect raised neutrophil levels, low lymphocyte levels, or both. Raised neutrophil levels are an adverse prognostic marker in NSCLC, melanoma, renal cell carcinoma and others [147-150]. Lymphocytes, however, are fundamental to 


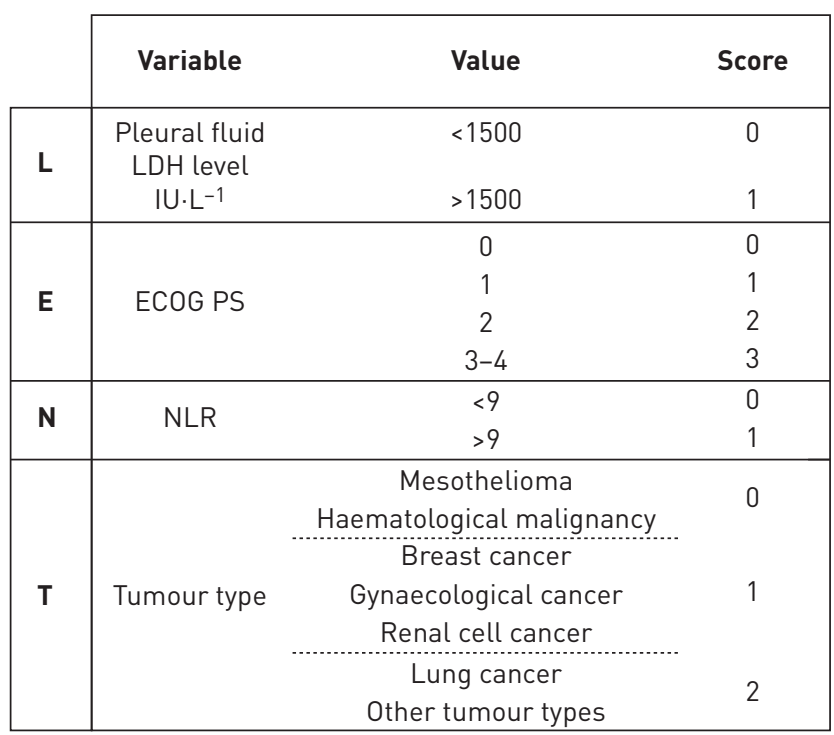

\begin{tabular}{|cc|}
\hline Risk category & Total score \\
\hline Low risk & $0-1$ \\
\hline Moderate risk & $2-4$ \\
\hline High risk & $5-7$ \\
\hline
\end{tabular}

FIGURE 1 The LENT score calculation and prognostic groups [45]. LDH: lactate dehydrogenase; ECOG PS: Eastern Cooperative Oncology Group performance status; NLR: neutrophil lymphocyte ratio.

immune-mediated cancer control and low counts result in less effective tumour destruction and worse survival [151-153]. The NLR combines these two variables to provide a simple prognostic value that has been shown to be accurate in many cancers [41, 145, 154-160].

Chronic inflammation causes catabolism and cachexia, which have further negative implications in MPE [141-143]. Low albumin has been shown to be an independent prognostic factor, as well as predicting outcome as part of the Prognostic Nutritional Index, a validated predictor of survival in mesothelioma and other malignancies [144, 145, 161-163].

Many prognostic scoring systems have been suggested for MPE. However, only one has been externally validated. The LENT score was developed using data from 789 patients across three international centres [156]. Baseline factors were analysed for prognostic value and those with the strongest predictive ability were included in the predictive model (figure 1). Final scores separated patients into low-, moderate- or high-risk groups, with median survival of 319, 130 and 44 days respectively. Validation produced similar results, confirming that LENT is an accurate and robust tool for predicting MPE prognosis. The simplicity of the score makes it attractive for both clinical practice and research settings.

\section{Prognostication in mesothelioma}

Multiple observational studies have reported prognostic factors in mesothelioma, although many were susceptible to selection bias, having been undertaken in selected populations [164-171]. The forthcoming ERS task force statement on mesothelioma contains information on prognostication, and therefore a full summary of the literature is not replicated here.

In brief, certain factors are consistently associated with survival in mesothelioma, i.e. sex, age, epithelioid differentiation, PS and tumour stage [117, 157, 164-170, 172-181]. However, for other factors, including presenting symptoms or quantification of asbestos exposure, the relationship with survival is less clear $[163,165,168,173,182-184]$. Multiple inflammatory markers correlate with survival, including white cell count $[121,145,157,162,166,168-170]$, platelet count $[157,164,166,169,170,172,177]$, C-reactive protein $[157,164,166,169,170,172,177]$, platelet to lymphocyte ratio [145] and lymphocyte to monocyte ratio [162]. Local inflammation also affects prognosis, with lymphocytic infiltration of tumours and tumour stroma associated with longer survival following surgery [153, 158]. Much work has been done investigating potential prognostic biomarkers, including mesothelin, osteopontin and megakaryocyte potentiating factor. However, heterogeneity in thresholds and sampling intervals mean that these tests are not yet sufficiently reliable to be employed in standard care [159, 185-187].

Numerous unvalidated prognostic indices exist in the literature [138, 157, 170, 171, 182, 183, 188-191], but only three have been externally validated $[169,183,192]$. Of the validated scores, two used pooled data from clinical trials and consequently have limited generalisability to the overall mesothelioma population [169, 183]. In contrast, BRIMs et al. [192] used an unselected cohort of 482 sequential mesothelioma 


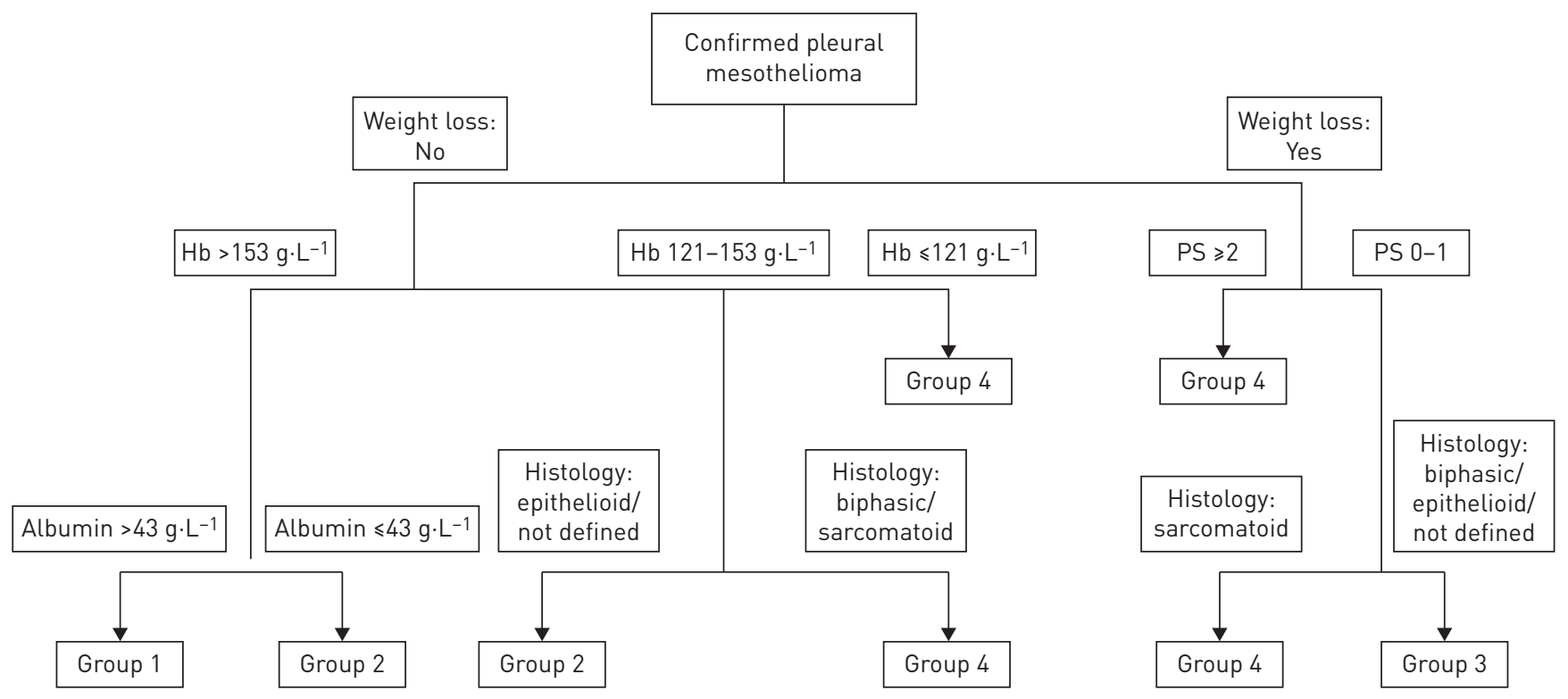

FIGURE 2 Brims' decision tree for predicting mesothelioma prognosis [192]. Hb: haemoglobin; PS: Eastern Cooperative Oncology Group performance status.

patients to develop their prognostic tree, which was then validated in a separate consecutive cohort, creating a more representative and clinically useful tool. The resultant decision tree separated patients into one of four prognostic groups, with survival falling from 34 months in Group 1 to $17.7,12.0$ and 7.4 months in subsequent groups (figure 2). The model showed reasonable accuracy for predicting death at 18 months, with $94.5 \%$ sensitivity and $76 \%$ positive predictive value.

\section{In summary}

Multiple baseline factors predict prognosis, including tumour type, stage, PS and inflammatory markers in blood and pleural fluid. Although multiple prognostic tools have been published, only the LENT score has been validated in MPE, and Brims' decision tree is the most clinically useful in mesothelioma.

\section{Question 5: should patients with malignant pleural effusion and cancer that is sensitive to oncological treatment le.g. chemotherapy, immunotherapy, targeted therapy) receive treatment prior to definitive management of their malignant pleural effusion? If so, which cancers?}

To date, no international guidelines recommend the use of antitumour medical treatment, e.g. chemotherapy, targeted therapy and/or immunotherapy, before standard palliative procedures for MPE management. Additionally, no randomised controlled trials were identified that compared palliative procedures for MPE with antitumour treatment.

However, observational studies suggest chemotherapy may be an effective first-line treatment in certain treatment-sensitive tumour types. For example, a retrospective study in small cell lung cancer (SCLC) demonstrated resolution of MPE following first-line chemotherapy in 34 of 62 patients (55\%) [193]. In contrast, another series of 30 patients with MPE due to SCLC reported increased myelosuppression following chemotherapy compared with 30 matched patients without MPE [194]. Whilst association should not be mistaken for causality, this observation supports the hypothesis that chemotherapy may accumulate in undrained effusions, leading to increased toxicity [193-195]. Consequently, the authors recommend that effusions be drained prior to commencing systemic chemotherapy.

By contrast, in lymphoma, case reports have suggested systemic therapy may be an effective treatment for MPE [196, 197], whilst another retrospective study reported control of MPE in 20 patients with T-cell lymphoblastic lymphoma who were treated with various systemic agents and mediastinal radiotherapy [198]. In NSCLC, several retrospective studies have described the role of systemic chemotherapy in patients with MPE; however, the significant selection bias affecting these studies precludes meaningful clinical interpretation [199-201]. Finally, a single case report describes complete resolution of MPE following initiation of chemotherapy in a patient with metastatic ovarian cancer [202]. 
Molecular targeted therapy has been investigated in patients with MPE and NSCLC [203-205]. A case report described the disappearance of MPE secondary to lung adenocarcinoma following treatment with bevacizumab, carboplatin and paclitaxel [205]. In a single-arm prospective study, 76 patients with MPE and EGFR mutations were treated with oral gefitinib (an EGFR tyrosine kinase inhibitor (TKI)) until disease progression, toxicity or withdrawal [203]. MPE were assessed with CT scans every 3 months. Of the 76 patients, $70(92 \%)$ had a reduction in MPE of $>50 \%$ that lasted at least 3 months. However, 48 developed subsequent MPE recurrence and 33 went on to receive talc pleurodesis. Another study, retrospective and non-randomised, added the anti-VEGF monoclonal antibody bevacizumab to chemotherapy alone or to chemotherapy plus EGFR-TKI in 86 patients with MPE due to EGFR-positive NSCLC with acquired EGFR-TKI resistance [204]. Progression-free survival was longer in the bevacizumab/EGFR-TKI/chemotherapy group (6.3 versus 4.8 months, $\mathrm{p}=0.048)$, and longer still in patients with acquired T790M mutations treated with the triple regimen (6.9 versus 4.6 months, $\mathrm{p}=0.022$ ). However, there was no difference in overall survival between the treatments. Selection bias is likely to have affected the results of both studies, and prospective randomised trials are needed to further clarify the role of targeted therapies in MPE with specific mutations.

A number of trials have investigated intra-pleural targeted therapies in MPE. Two phase I studies explored the safety of intravenous and intra-pleural chemotherapy alongside monoclonal antibodies in MPE [206, 207]. Safety profiles were variable and numbers were too small to comment on efficacy. Two randomised phase II studies have investigated intra-plural use of bevacizumab in patients with NSCLC and MPE [208, 209]. In one, a combination of bevacizumab and paclitaxel were administered intra-pleurally, leading to reduced pleural effusion size and improved symptoms in $78.6 \%$ of patients compared with $50 \%$ treated with intra-pleural paclitaxel alone [208]. The 1-year survival rate was higher in the bevacizumab arm (45.8\% versus $20.8 \%$ ), whilst adverse events were similar between the groups. The second phase II trial compared intra-pleural cisplatin with or without bevacizumab in 70 patients with MPE in non-squamous NSCLC [209]. Better MPE response rates (85.7\% versus 56.6\%) were seen with the addition of bevacizumab. A single-arm phase II study used intravenous bevacizumab alongside systemic carboplatin-pemetrexed chemotherapy and demonstrated MPE control in 21 out of 23 patients (91.3\%) [210]. Again, further research is needed to determine the efficacy of this approach.

\section{In summary}

The current literature is limited, consisting mainly of small retrospective series or single-arm prospective studies. Thus no conclusions can be drawn on the value of antitumour treatment in MPE management. Because there is no strong evidence to suggest any detriment associated with standard interventional management of MPE, this is likely to remain the first line of treatment until evidence emerges to support alternative approaches. Further studies are needed, specifically to confirm the use of intra-pleural bevacizumab in NSCLC MPE and EGFR-TKI in patients with MPE due to NSCLC with mutated EGFR.

\section{Question 6: in order to determine treatment in malignant pleural effusion, is a histological diagnosis always required or is cytology sufficient?}

The aim of cytological and histological investigations is twofold: to obtain a diagnosis and to determine therapeutic options. As cancer treatment options expand to include targeted therapies, immunotherapy and personalised treatments, the question of which investigation yields the most pathological information has become increasingly pertinent.

The diagnostic yield of pleural fluid cytology varies depending on tumour type, tumour load, sample quality, expertise of cytologist and availability of specific ancillary tests, e.g. gene expression. The mean diagnostic sensitivity of pleural fluid cytology for malignancy is between $49 \%$ and $91 \%$, with maximal yield from two separate samples [211-221]. Cytology has the highest diagnostic yield for adenocarcinoma, compared with mesothelioma, for which sensitivity is generally accepted to be $\sim 30 \%$, but may fall as low as $16 \%$ [215-217]. With respect to mesothelioma, cytological diagnosis is particularly challenging given that tissue invasion is not always present and histological subtypes can be difficult to differentiate [222]. The yield of cytological diagnosis in epithelioid mesothelioma is higher in the presence of visceral pleural invasion [223].

Analysing larger volumes of pleural fluid may improve diagnostic sensitivity in MPE, although there appears to be a threshold. Several studies confirmed that submitting $>75 \mathrm{~mL}$ of pleural fluid for cytological examination does not improve the yield when using the direct smear method [224-226]. However, if both direct smear/cytospin and cellblock preparations are utilised, up to $150 \mathrm{~mL}$ is recommended [227]. This combined method has been shown to offer additional value compared to smear slides alone [228, 229].

Initial cytological evaluation of pleural fluid involves identifying cells and characterising them as benign/reactive or malignant based on morphological and immunohistochemical parameters. If malignant cells are seen, 
TABLE 2 Immunohistochemical markers with high specificity for differentiating tumour types in malignant pleural effusion

\begin{tabular}{llll} 
Mesothelial markers & Adenocarcinoma markers & $\begin{array}{l}\text { Squamous-cell } \\
\text { carcinoma markers }\end{array}$ & Organ-specific markers \\
\hline Calretinin & CEA & P40 & Lung: TTF-1, Napsin A \\
CK5/6 & B27.3 & P63 & Prostate: PSA, PSMA \\
D2-40 (podoplanin) & Bg8 & CK5/6 & Kidney: PAX-2, PAX-8, RCC, CAIX \\
WT-1 & BerEP4 & & Pancreas: CA 19-9 \\
& MOC-31 & & Gastrointestinal: CDX-2, CK20 \\
& & & Gynaecological: PAX-8, WT1 \\
& & Breast: Mammaglobin, GCDFP-15, ER, PR, GATA3
\end{tabular}

further evaluation is required to determine their origin, i.e. primary pleural malignancy versus metastatic disease. Disease-specific immunochemical markers are summarised in table 2 [230-234].

Flow cytometry may be a useful adjunct in the differentiation of lymphoma in pleural fluid [235, 236]. However, its role in the diagnosis of non-lymphoma MPE has not been fully established, with studies demonstrating variable sensitivities of between 50\% and 94\% [237-239]. Further innovative approaches may advance this technique in future [240].

Where mesothelioma is suspected, specific tests are frequently required owing to the complexities associated with making this diagnosis. Sarcomatoid mesothelioma is particularly difficult to diagnose because tests for mesothelial markers are often negative. Additionally, there are no specific antibodies that differentiate between sarcomatoid mesothelioma and other sarcoma-type tumours, although GATA3 has shown early promise in one small study [241]. Loss of BAP1 expression and homozygous deletion of p16 detected by fluorescent in situ hybridisation are highly specific indicators for mesothelioma, but negative results do not exclude the diagnosis [242-245]. These tests can be undertaken on both pleural fluid and biopsy samples, although sensitivity is reduced if no atypical mesothelial cells are present in effusion samples [243-245]. Consequently, although some laboratories are confident making definitive cytological diagnoses [218, 246], the International Mesothelioma Interest Group recommends that the diagnosis should always be based on biopsy [232]. Evaluation of biopsy tissue can also provide prognostic information in mesothelioma because certain histological features, such as nuclear atypia and mitotic index, correlate with prognosis in epithelioid disease [247-250].

Mesothelioma aside, the pauci-cellular nature of pleural fluid often results in insufficient cells on which to perform the necessary tests to confirm the diagnosis [251]. Additionally, tissue-specific gene expression and receptor status profiling may be required to assess suitability for therapeutic options such as molecular therapies, and pleural fluid alone is rarely sufficient for this. Whilst newer molecular profiling technologies such as high-throughput, next-generation and Sanger sequencing have shown promise in detecting genetic mutations on MPE cell blocks, they require further investigation before widespread adoption into clinical practice [251-254]. Consequently, pleural biopsy is usually necessary to provide sufficient tissue for analysis. Thoracoscopic pleural biopsies have a diagnostic sensitivity of $>92 \%$ for malignancy, and consistently outperform cytological examination, even when cell block preparation is performed [255-257].

Even though pleural biopsy is the gold standard for diagnosing pleural malignancy, false negative results can occur. Observational follow-up studies of patients whose original biopsies showed nonspecific pleuritis found that up to $15 \%$ were subsequently diagnosed with pleural malignancy, most frequently mesothelioma [258-262]. The decision on whether to undertake repeat biopsies, possibly via a different approach, is usually made based on clinical suspicion and individual patient factors (e.g. suitability for surgery). Whatever pathway is chosen, many clinicians elect to undertake long-term radiological monitoring to ensure malignancy is not missed.

Recently, highly sensitive assays have been developed which allow the identification of circulating cell-free tumour DNA, tumour RNA (especially microRNAs) and circulating tumour cells from patients' blood samples $[263,264]$. These "liquid biopsy" methods have proven useful in lung cancer patients in detecting baseline EGFR mutations $[265,266]$, and for identifying mutations conferring resistance to targeted therapy, e.g. T790M EGFR mutation [267, 268]. Whilst several of these assays have been approved by regulatory authorities for use in clinical care, they are not yet universally accessible. Furthermore, for some tumours, e.g. mesothelioma, no standardised approach has been developed and further studies are needed [269-271]. 


\section{In summary}

Cytology can provide useful diagnostic, prognostic and therapeutic information; however, low sensitivity remains an issue, especially in mesothelioma. Pleural biopsy remains the gold standard, although in cases where initial biopsies yield inflammation, repeat biopsy or extended follow-up is usually required. Newer technologies such as liquid biopsy may negate the need for biopsies in future, but further research is needed to ascertain their optimal role.

\section{Conclusions}

This task force statement aimed to review the literature relating to the management of MPE, focusing specifically on issues that may be relevant to respiratory physicians, thoracic surgeons and oncologists in routine clinical practice.

The highest quality evidence for the optimal treatment of symptomatic MPE suggests that both talc pleurodesis (via slurry or poudrage) and IPCs are highly effective and significantly improve symptoms. It is still unclear whether talc poudrage is more effective than talc slurry, and whilst IPCs reduce time in hospital, they are associated with a modest increase in adverse events with long-term use.

In the context of trapped lung, evidence is lacking with regard to effective treatment options. IPCs often improve symptoms, but prospective randomised trials are required. Similarly, options are limited in loculated MPE, with little evidence to suggest that intra-pleural fibrinolysis has any sustained effect on patient symptoms and well-being.

Regarding prognostication, the LENT score is a simple, validated tool for predicting survival in MPE, whilst Brims' decision tree is most useful in mesothelioma. At present, there is no robust evidence to support the use of oncological therapies as an alternative to mechanical drainage, although further research is required. Currently, although cytological analysis can provide some diagnostic information in MPE, tissue biopsy remains the gold standard.

The management of MPE has advanced significantly since the most recent international guidelines were published, with several high-quality randomised controlled trials providing robust evidence to inform clinical practice. However, a number of unanswered questions remain, and ongoing research is required in order for clinicians to provide optimal care for this patient group.

Acknowledgements: The task force are very grateful to Kath Wright for her help with the literature search and to Georgia Karpathiou for her input and advice on Question 6.

Conflict of interest: A.C. Bibby reports grants from National Institute of Health Research (DRF-2016-09-065), outside the submitted work. I. Psallidas is a Medical Science Director for AstraZeneca in a different research area than the submitted work. P. Licht reports personal fees (speaker's honorarium) from Ethicon, outside the submitted work. A. Scherpereel reports personal fees (for advisory board participation) from BMS, MSD, Boehringer Ingelheim and Roche, and has been an investigator in clinical trials (fees paid to institution, CHU de Lille, France) for AstraZeneca, Lilly, BMS, MSD, Boehringer Ingelheim and Roche, outside the submitted work. N.M. Rahman reports personal fees for consultancy work from Rocket Medical UK, outside the submitted work. N.A. Maskell reports unrestricted research grants from Becton Dickinson and Rocket, outside the submitted work, and is a member of the advisory board for Becton Dickinson.

\section{References}

1 Clive AOJ, Bhatnagar R, Preston NJ, et al. Interventions for the management of malignant pleural effusions: a network meta-analysis. Cochrane Database Syst Rev 2016; (5): CD010529.

2 Roberts ME, Neville E, Berrisford RG, et al. Management of a malignant pleural effusion: British Thoracic Society pleural disease guideline 2010. Thorax 2010; 65: Suppl. 2, ii32-ii40.

3 Davies HE, Mishra EK, Kahan BC, et al. Effect of an indwelling pleural catheter vs chest tube and talc pleurodesis for relieving dyspnea in patients with malignant pleural effusion: the TIME2 randomized controlled trial. JAMA 2012; 307: 2383-2389.

4 Rahman NM, Pepperell J, Rehal S, et al. Effect of opioids vs NSAIDs and larger vs smaller chest tube size on pain control and pleurodesis efficacy among patients with malignant pleural effusion: the TIME1 randomized clinical trial. JAMA 2015; 314: 2641-2653.

5 Rintoul RC, Ritchie AJ, Edwards JG, et al. A multi-centre randomised controlled trial of video assisted thoracoscopic pleurectomy versus talc pleurodesis in malignant pleural mesothelioma. J Thorac Oncol 2013; 8: S2-S3.

6 Bucknor A, Harrison-Phipps K, Davies T, et al. Is silver nitrate an effective means of pleurodesis? Interact Cardiovasc Thorac Surg 2015; 21: 521-525.

7 da Silveira Paschoalini M, Vargas FS, Marchi E, et al. Prospective randomized trial of silver nitrate vs talc slurry in pleurodesis for symptomatic malignant pleural effusions. Chest 2005; 128: 684-689.

8 Menna C, Andreetti C, Ibrahim M, et al. The effect of silver nitrate pleurodesis after a failed thoracoscopic talc poudrage. Biomed Res Int 2013; 2013: 295890.

9 Tan C, Sedrakyan A, Browne J, et al. The evidence on the effectiveness of management for malignant pleural effusion: a systematic review. Eur J Cardiothorac Surg 2006; 29: 829-838. 
13

Mummadi SK, Kumbam A, Hahn PY. Malignant pleural effusions and the role of talc poudrage and talc slurry: a systematic review and meta-analysis. F1000Research 1000; 3: 254.

Dresler CM, Olak J, Herndon JE 2nd, et al. Cooperative Groups Cancer and Leukemia Group B; Eastern Cooperative Oncology Group; North Central Cooperative Oncology Group; Radiation Therapy Oncology Group. Phase III intergroup study of talc poudrage vs talc slurry sclerosis for malignant pleural effusion. Chest 2005; 127 : 909-915.

Yim AP, Chan AT, Lee TW, et al. Thoracoscopic talc insufflation versus talc slurry for symptomatic malignant pleural effusion. Ann Thorac Surg 1996; 62: 1655-1658.

Terra RM, Junqueira JJM, Teixeira LR, et al. Is full postpleurodesis lung expansion a determinant of a successful outcome after talc pleurodesis? Chest 2009; 136: 361-368.

Benkó I, Molnár TF, Horváth OP. Palliative treatment of malignant pleural effusions by video-assisted thoracoscopic surgery. Acta Chir Hung 1999; 38: 131-133.

Debeljak A, Kecelj P, Triller N, et al. Talc pleurodesis: comparison of talc slurry instillation with thoracoscopic talc insufflation for malignant pleural effusions. J BUON 2006; 11: 463-467.

Stefani A, Natali P, Casali C, et al. Talc poudrage versus talc slurry in the treatment of malignant pleural effusion. A prospective comparative study. Eur J Cardiothorac Surg 2006; 30: 827-832.

Luh SP, Chen CY, Tzao CY. Malignant pleural effusion treatment outcomes: pleurodesis via video-assisted thoracic surgery (VATS) versus tube thoracostomy. Thorac Cardiovasc Surg 2006; 54: 332-336.

Jancovici R, Lang-Lazdunski L, Pons F, et al. Complications of video-assisted thoracic surgery: a five-year experience. Ann Thorac Surg 1996; 61: 533-537.

Cardillo G, Facciolo F, Carbone L, et al. Long-term follow-up of video-assisted talc pleurodesis in malignant recurrent pleural effusions. Eur J Cardiothorac Surg 2002; 21: 302-305; discussion 305-306.

Canto A, Guijarro R, Arnau A, et al. Videothoracoscopy in the diagnosis and treatment of malignant pleural mesothelioma with associated pleural effusions. Thorac Cardiovasc Surg 1997; 45: 16-19.

Steger V, Mika U, Toomes H, et al. Who gains most? A 10-year experience with 611 thoracoscopic talc pleurodeses. Ann Thorac Surg 2007; 83: 1940-1945.

Janssen JP, Collier G, Astoul P, et al. Safety of pleurodesis with talc poudrage in malignant pleural effusion: a prospective cohort study. Lancet 2007; 369: 1535-1539.

de Campos JR, Vargas FS, de Campos Werebe E, et al. Thoracoscopy talc poudrage: a 15-year experience. Chest 2001; 119: 801-806.

Barbetakis N, Asteriou C, Papadopoulou F, et al. Early and late morbidity and mortality and life expectancy following thoracoscopic talc insufflation for control of malignant pleural effusions: a review of 400 cases. J Cardiothorac Surg 2010; 5: 27.

Viallat JR, Rey F, Astoul P, et al. Thoracoscopic talc poudrage pleurodesis for malignant effusions. A review of 360 cases. Chest 1996; 110: 1387-1393.

Koledin M, Duric D, Milovancev A, et al. Pleural effusions of malignant etiology: diagnostics, treatment and quality of life. Arch Oncol 2001; 9: 3-7.

Agrawal A, Tandon R, Lalit S, et al. Clinico-pathological profile and course of malignant pleural effusion in a tertiary care teaching hospital in western U.P. with special reference to lung cancer. Lung India 2015; 32: 326-330.

Arapis K, Caliandro R, Stern JB, et al. Thoracoscopic palliative treatment of malignant pleural effusions: results in 273 patients. Surg Endosc 2006; 20: 919-923.

Bal S, Hasan SS. Thoracoscopic management of malignant pleural effusion. Int Surg 1993; 78: 324-327.

Trotter D, Aly A, Siu L, et al. Video-assisted thoracoscopic (VATS) pleurodesis for malignant effusion: an Australian teaching hospital's experience. Heart Lung Circ 2005; 14: 93-97.

Sanchez-Armengol A, Rodriguez-Panadero F. Survival and talc pleurodesis in metastatic pleural carcinoma, revisited. Chest 1993; 104: 1482-1485.

Schniewind B, Rose T, Woltmann N, et al. Clinical outcomes and health-related quality of life after thoracoscopic talc pleurodesis. J Palliat Med 2012; 15: 37-42.

Kolschmann S, Ballin A, Gillissen A. Clinical efficacy and safety of thoracoscopic talc pleurodesis in malignant pleural effusions. Chest 2005; 128: 1431-1435.

Schulze M, Boehle AS, Kurdow R, et al. Effective treatment of malignant pleural effusion by minimal invasive thoracic surgery: thoracoscopic talc pleurodesis and pleuroperitoneal shunts in 101 patients. Ann Thorac Surg 2001; 71: 1809-1812.

Clementsen P, Evald T, Grode G, et al. Treatment of malignant pleural effusion: pleurodesis using a small percutaneous catheter. A prospective randomized study. Respir Med 1998; 92: 593-596.

Mager H-J, Maesen B, Verzijlbergen F, et al. Distribution of talc suspension during treatment of malignant pleural effusion with talc pleurodesis. Lung Cancer 2002; 36: 77-81.

Arellano-Orden E, Romero-Falcon A, Juan JM, et al. Small particle-size talc is associated with poor outcome and increased inflammation in thoracoscopic pleurodesis. Respiration 2013; 86: 201-209.

Habal P, Omran N, Jankovicova K, et al. Predictive value of systemic and local inflammation parameters in talc pleurodesis assessment. Biomed Pap Med Fac Univ Palacky Olomouc Czech Repub 2015; 159: 234-241.

Rodriguez-Panadero F, Segado A, Martin Juan J, et al. Failure of talc pleurodesis is associated with increased pleural fibrinolysis. Am J Respir Crit Care Med 1995; 151: 785-790.

Korsic MB, Badovinac S, Cucevic B, et al. Talc pleurodesis improves survival of patients with malignant pleural effusions: case-control study. Wien Klin Wochenschr 2015; 127: 963-969.

Yoon DW, Cho JH, Choi YS, et al. Predictors of survival in patients who underwent video-assisted thoracic surgery talc pleurodesis for malignant pleural effusion. Thorac Cancer 2016; 7: 393-398.

Friedel G, Linder A, Toomes H. Video-assisted thoracoscopic pleurectomy as therapy for recurring malignant pleural effusion. Minim Invasive Ther 1994; 3: 169-172.

Waller DA, Morritt GN, Forty J. Video-assisted thoracoscopic pleurectomy in the management of malignant pleural effusion. Chest 1995; 107: 1454-1456.

Ohta Y, Oda M, Shimizu J, et al. Multimodality treatment including parietal pleurectomy as a possible therapeutic procedure for malignant pleural effusion. Surg Technol Int 2007; 16: 184-189. 

pleurodesis in patients with breast carcinoma. Eur J Cardiothorac Surg 2004; 26: 432-436.

46 Hojski A, Leitgeb M, Crnjac A. Release of growth factors after mechanical and chemical pleurodesis for treatment of malignant pleural effusion: a randomized control study. Radiol Oncol 2015; 49: 386-394.

$47 \mathrm{Gu} \mathrm{LJ}$, Wang WJ. [Comparative study of video-assisted thoracoscopic surgery vs thoracic tube drainage in synthetic therapy for malignant pleural effusion secondary to non-small cell lung cancer]. Nan Fang Yi Ke Da Xue Xue Bao 2006; 26: 1023-1026.

48 Bernard A, de Dompsure Régis B, Hagry O, et al. Early and late mortality after pleurodesis for malignant pleural effusion. Ann Thorac Surg 2002; 74: 213-217.

49 Mineo TC, Francesco S, Federico T, et al. Quality of life and outcomes after nonintubated versus intubated video-thoracoscopic pleurodesis for malignant pleural effusion: comparison by a case-matched study. J Palliat Med 2014; 17: 761-768

50 Ost DE, Jimenez CA, Lei X, et al. Quality-adjusted survival following treatment of malignant pleural effusions with indwelling pleural catheters. Chest 2014; 145: 1347-1356.

51 Warren WH, Kalimi R, Khodadadian LM, et al. Management of malignant pleural effusions using the Pleur catheter. Ann Thorac Surg 2008; 85: 1049-1055.

52 Tremblay AM, Michaud G. Single-center experience with 250 tunnelled pleural catheter insertions for malignant pleural effusion. Chest 2006; 129: 362-368.

53 Sabur NF, Chee A, Stather DR, et al. The impact of tunneled pleural catheters on the quality of life of patients with malignant pleural effusions. Respiration 2013; 85: 36-42.

54 Gilbert CR, Lee HJ, Skalski JH, et al. The use of indwelling tunneled pleural catheters for recurrent pleural effusions in patients with hematologic malignancies: a multicenter study. Chest 2015; 148: 752-758.

55 Bazerbashi S, Villaquiran J, Awan MY, et al. Ambulatory intercostal drainage for the management of malignant pleural effusion: a single center experience. Ann Surg Oncol 2009; 16: 3482-3487.

56 Van Meter MEM, McKee KY, Kohlwes RJ. Efficacy and safety of tunneled pleural catheters in adults with malignant pleural effusions: a systematic review. J Gen Intern Med 2011; 26: 70-76.

57 Putnam JB Jr, Light RW, Rodriguez RM, et al. A randomized comparison of indwelling pleural catheter and doxycycline pleurodesis in the management of malignant pleural effusions. Cancer 1999; 86: 1992-1999.

58 Thomas R, Fysh EH, Smith NA, et al. Effect of an indwelling pleural catheter vs talc pleurodesis on hospitalization days in patients with malignant pleural effusion: the AMPLE randomized clinical trial. JAMA 2017; 318: 1903-1912.

59 Demmy TL, Gu L, Burkhalter JE, et al. Optimal management of malignant pleural effusions (results of CALGB 30102). J Natl Compr Canc Netw 2012; 10: 975-982.

60 Hunt BM, Farivar AS, Vallières E, et al. Thoracoscopic talc versus tunneled pleural catheters for palliation of malignant pleural effusions. Ann Thorac Surg 2012; 94: 1053-1057; discussion 1057-1059.

61 Fysh ETHW, Waterer GW, Kendall PA, et al. Indwelling pleural catheters reduce inpatient days over pleurodesis for malignant pleural effusion. Chest 2012; 142: 394-400.

62 Bell D, Wright G. A retrospective review of the palliative surgical management of malignant pleural effusions. BMJ Support Palliat Care 2014; 4: 161-166.

63 Walker S, Zubrinic M, Massey CZ, et al. A prospective study of patient-centred outcomes in the management of malignant pleural effusions. Int J Palliat Nurs 2016; 22: 351-358.

64 Wahidi MM, Reddy C, Yarmus L, et al. Randomized trial of pleural fluid drainage frequency in patients with malignant pleural effusions. The ASAP trial. Am J Respir Crit Care Med 2017; 195: 1050-1057.

65 Schneider T, Reimer P, Storz K, et al. Recurrent pleural effusion: who benefits from a tunneled pleural catheter? Thorac Cardiovasc Surg 2009; 57: 42-46.

66 Boujaoude Z, Bartter T, Abboud M, et al. Pleuroscopic pleurodesis combined with tunneled pleural catheter for management of malignant pleural effusion: a prospective observational study. J Bronchology Interv Pulmonol 2015; 22: 237-243.

67 Reddy C, Ernst A, Lamb C, et al. Rapid pleurodesis for malignant pleural effusions: a pilot study. Chest 2011; 139: 1419-1423.

68 Freeman RK, Anthony JA, Raja SM. A propensity-matched comparison of pleurodesis or tunneled pleural catheter in patients undergoing diagnostic thoracoscopy for malignancy. Ann Thorac Surg 2013; 96: 259-263: discussion 263-264.

69 Bhatnagar R, Laskawiec-Szkonter M, Piotrowska HEG, et al. Evaluating the efficacy of thoracoscopy and talc poudrage versus pleurodesis using talc slurry (TAPPS trial): protocol of an open-label randomised controlled trial. BMJ Open 2014; 4: e007045.

70 Rintoul RC, Ritchie AJ, Edwards JG, et al. Efficacy and cost of video-assisted thoracoscopic partial pleurectomy versus talc pleurodesis in patients with malignant pleural mesothelioma (MesoVATS): an open-label, randomised, controlled trial. Lancet 2014; 384: 1118-1127.

Huggins JT, Doelken P, Sahn SA. The unexpandable lung. F1000 Med Rep 2010; 2: 77.

Doelken P. Clinical implications of unexpandable lung due to pleural disease. Am J Med Sci 2008; 335: 21-25.

Lan R-S, Lo SK, Chuang M-L, et al. Elastance of the pleural space: a predictor for the outcome of pleurodesis in patients with malignant pleural effusion. Ann Intern Med 1997; 126: 768-774.

74 Huggins JT, Doelken P. Pleural manometry. Clin Chest Med 2006; 27: 229-240.

75 Feller-Kopman D. Therapeutic thoracentesis: the role of ultrasound and pleural manometry. Curr Opin Pulm Med 2007; 13: 312-318.

76 Boshuizen RC, Sinaasappel M, Vincent AD, et al. Pleural pressure swing and lung expansion after malignant pleural effusion drainage: the benefits of high-temporal resolution pleural manometry. J Bronchology Interv Pulmonol 2013; 20: 200-205.

77 Feller-Kopman D, Walkey A, Berkowitz D, et al. The relationship of pleural pressure to symptom development during therapeutic thoracentesis. Chest 2006; 129: 1556-1560.

78 Salamonsen MR, Lo AK, $\mathrm{Ng} \mathrm{AC}$, et al. Novel use of pleural ultrasound can identify malignant entrapped lung prior to effusion drainage. Chest 2014; 146: 1286-1293. 
Zahid I, Routledge T, Bille A, et al. What is the best treatment for malignant pleural effusions? Interact Cardiovasc Thorac Surg 2011; 12: 818-823.

Pien GW, Gant MJ, Washam CL, et al. Use of an implantable pleural catheter for trapped lung syndrome in patients with malignant pleural effusion. Chest 2001; 119: 1641-1646.

Ohm C, Park D, Vogen M, et al. Use of an indwelling pleural catheter compared with thorascopic talc pleurodesis in the management of malignant pleural effusions. Am Surg 2003; 69: 198-202; discussion 202.

Qureshi RA, Collinson SL, Powell RJ, et al. Management of malignant pleural effusion associated with trapped lung syndrome. Asian Cardiovasc Thorac Ann 2008; 16: 120-123.

van den Toorn LM, Schaap E, Surmont VF, et al. Management of recurrent malignant pleural effusions with a chronic indwelling pleural catheter. Lung Cancer 2005; 50: 123-127.

Burgers JA, Olijve A, Baas P. [Chronic indwelling pleural catheter for malignant pleural effusion in 25 patients]. Ned Tijdschr Geneeskd 2006; 150: 1618-1623.

Efthymiou CA, Masudi T, Thorpe JAC, et al. Malignant pleural effusion in the presence of trapped lung Five-year experience of PleurX tunnelled catheters. Interact Cardiovasc Thorac Surg 2009; 9: 961-964.

Petrou M, Kaplan D, Goldstraw P. Management of recurrent malignant pleural effusions: the complementary role of talc pleurodesis and pleuroperitoneal shunting. Cancer 1995; 75: 801-805.

Genc O, Petrou M, Ladas G, et al. The long-term morbidity of pleuroperitoneal shunts in the management of recurrent malignant effusions. Eur J Cardiothorac Surg 2000; 18: 143-146.

Yim AP, Ho JK, Lee TW, et al. Thoracoscopic management of pleural effusions revisited. Aust N Z J Surg 1995; 65: 308-311.

Hsu LH, Soong TC, Feng AC, et al. Intrapleural urokinase for the treatment of loculated malignant pleural effusions and trapped lungs in medically inoperable cancer patients. J Thorac Oncol 2006; 1: 460-467.

Chung C-L, Chen C-H, Sheu J-R, et al. Proinflammatory cytokines, transforming growth factor- $\beta 1$, and fibrinolytic enzymes in loculated and free-flowing pleural exudates. Chest 2005; 128: 690-697.

Sioris T, Sihvo E, Salo J, et al. Long-term indwelling pleural catheter (PleurX) for malignant pleural effusion unsuitable for talc pleurodesis. Eur J Surg Oncol 2009; 35: 546-551.

Bielsa S, Martin-Juan J, Porcel JM, et al. Diagnostic and prognostic implications of pleural adhesions in malignant effusions. J Thorac Oncol 2008; 3: 1251-1256.

Mason AC, Miller BH, Krasna MJ, et al. Accuracy of CT for the detection of pleural adhesions: correlation with video-assisted thoracoscopic surgery. Chest 1999; 115: 423-427.

Cassanelli N, Caroli G, Dolci G, et al. Accuracy of transthoracic ultrasound for the detection of pleural adhesions. Eur J Cardiothorac Surg 2012; 42: 813-818.

Wei B, Wang T, Jiang F, et al. Use of transthoracic ultrasound to predict pleural adhesions: a prospective blinded study. Thorac Cardiovasc Surg 2012; 60: 101-104.

Medford AR, Agrawal S, Bennett JA, et al. Thoracic ultrasound prior to medical thoracoscopy improves pleural access and predicts fibrous septation. Respirology 2010; 15: 804-808.

Kohan JM, Poe RH, Israel RH, et al. Value of chest ultrasonography versus decubitus roentgenography for thoracentesis. Am Rev Respir Dis 1986; 133: 1124-1126.

Havelock T, Teoh R, Laws D, et al. Pleural procedures and thoracic ultrasound: British Thoracic Society pleural disease guideline 2010. Thorax 2010; 65: Suppl. 2, i61-i76.

Silverman SG, Mueller PR, Saini S, et al. Thoracic empyema: management with image-guided catheter drainage. Radiology 1988; 169: 5-9.

Davies HE, Davies RJ, Davies CW. Management of pleural infection in adults: British Thoracic Society Pleural Disease Guideline 2010. Thorax 2010; 65: Suppl. 2, ii41-ii53.

VanSonnenberg E, Nakamoto S, Mueller P, et al. CT-and ultrasound-guided catheter drainage of empyemas after chest-tube failure. Radiology 1984; 151: 349-353.

Rahman NM, Maskell NA, West A, et al. Intrapleural use of tissue plasminogen activator and DNase in pleural infection. N Engl J Med 2011; 365: 518-526.

Balamugesh T, Christopher DJ, Rajesh T, et al. Fibrinolysis of loculated pleural effusion in malignant mesothelioma. Singapore Med J 2004; 45: 594-595.

Dixit R, Dixit K, Bansal R. Intrapleural streptokinase in multiloculated malignant pleural effusion. Indian J Chest Dis Allied Sci 2004; 46: 59-62.

Maskell NA, Gleeson FV. Images in clinical medicine. Effect of intrapleural streptokinase on a loculated malignant pleural effusion. $N$ Engl J Med 2003; 348: e4.

Jerjes-Sanchez C, Ramirez-Rivera A, Elizalde JJ, et al. Intrapleural fibrinolysis with streptokinase as an adjunctive treatment in hemothorax and empyema: a multicenter trial. Chest 1996; 109: 1514-1519.

Davies CW, Traill ZC, Gleeson FV, et al. Intrapleur.
multiloculated pleural effusions. Chest 1999; 115: 729-733. means of tube thoracostomy. Ann Thorac Surg 2011; 91: 860-864.

Gilkeson RC, Silverman P, Haaga JR. Using urokinase to treat malignant pleural effusions. AJR Am J Roentgenol 1999; 173: 781-783.

Abu-Daff S, Maziak DE, Alshehab D, et al. Intrapleural fibrinolytic therapy (IPFT) in loculated pleural effusions-analysis of predictors for failure of therapy and bleeding: a cohort study. BMJ Open 2013; 3: e001887.

Okur E, Baysungur V, Tezel C, et al. Streptokinase for malignant pleural effusions: a randomized controlled study. Asian Cardiovasc Thorac Ann 2011; 19: 238-243.

Saydam O, Karapinar K, Gokce M, et al. The palliative treatment with intrapleural streptokinase in patients with multiloculated malignant pleural effusion: a double-blind, placebo-controlled, randomized study. Med Oncol 2015; 32: 179.

13 Mishra DEK, Clive DAO, Wills MGH, et al. Randomised controlled trial of urokinase versus placebo for non-draining malignant pleural effusion. Am J Respir Crit Care Med 2017; 197: 502-508.

Thomas R, Piccolo F, Miller D, et al. Intrapleural fibrinolysis for the treatment of indwelling pleura catheter-related symptomatic loculations: a multicenter observational study. Chest 2015; 148: 746-751. 

Med 2000; 162: 1987-2001.

116 Heffner JE, Nietert PJ, Barbieri C. Pleural fluid $\mathrm{pH}$ as a predictor of survival for patients with malignant pleural effusions. Chest 2000; 117: 79-86.

117 Abakay A, Komek H, Abakay O, et al. Relationship between 18 FDG PET-CT findings and the survival of 177 patients with malignant pleural mesothelioma. Eur Rev Med Pharmacol Sci 2013; 17: 1233-1241.

118 Zamboni MM, da Silva CT, Baretta R, et al. Important prognostic factors for survival in patients with malignant pleural effusion. BMC Pulm Med 2015; 15: 29.

119 Bielsa S, Salud A, Martínez M, et al. Prognostic significance of pleural fluid data in patients with malignant effusion. Eur J Intern Med 2008; 19: 334-339.

120 Fentiman IS, Millis R, Sexton S, et al. Pleural effusion in breast cancer: a review of 105 cases. Cancer 1981; 47: 2087-2092.

121 Anevlavis S, Kouliatsis G, Sotiriou I, et al. Prognostic factors in patients presenting with pleural effusion revealing malignancy. Respiration 2014; 87: 311-316.

122 Edge S, Byrd D, Compton C, et al. American Joint Committee on Cancer. Staging manual. 7th Edn. New York, Springer, 2009.

123 Rusch VW, Chansky K, Kindler HL, et al. The IASLC Mesothelioma Staging Project: proposals for the M descriptors and for revision of the TNM stage groupings in the forthcoming (eighth) edition of the TNM classification for mesothelioma. J Thorac Oncol 2016; 11: 2112-2119.

124 Buccheri G, Ferrigno D, Tamburini M. Karnofsky and ECOG performance status scoring in lung cancer: a prospective, longitudinal study of 536 patients from a single institution. Eur J Cancer 1996; 32: 1135-1141.

125 Hwang SS, Scott CB, Chang VT, et al. Prediction of survival for advanced cancer patients by recursive partitioning analysis: role of Karnofsky performance status, quality of life, and symptom distress. Cancer Invest 2004; 22: 678-687.

126 Burrows CM, Mathews WC, Colt HG. Predicting survival in patients with recurrent symptomatic malignant pleural effusions: an assessment of the prognostic values of physiologic, morphologic, and quality of life measures of extent of disease. Chest 2000; 117: 73-78.

127 Oken MM, Creech RH, Tormey DC, et al. Toxicity and response criteria of the Eastern Cooperative Oncology Group. Am J Clin Oncol 1982; 5: 649-656.

128 Karnofsky DA, Burchenal JH. The clinical evaluation of chemotherapeutic agents in cancer. In: MacLeod CM, ed. Evaluation of Chemotherapeutic Agents. New York, Columbia University Press, 1949.

129 Martinez-Moragon E, Aparicio J, Sanchis J, et al. Malignant pleural effusion: prognostic factors for survival and response to chemical pleurodesis in a series of 120 cases. Respiration 1998; 65: 108-113.

130 Jiménez D, Díaz G, Gil D, et al. Etiology and prognostic significance of massive pleural effusions. Respir Med 2005; 99: 1183-1187.

131 Sahn SA, Good JT. Pleural fluid pH in malignant effusions. Diagnostic, prognostic, and therapeutic implications. Ann Intern Med 1988; 108: 345-349.

132 Sakr L, Maldonado F, Greillier L, et al. Thoracoscopic assessment of pleural tumor burden in patients with malignant pleural effusion: prognostic and therapeutic implications. J Thorac Oncol 2011; 6: 592-597.

133 Wu S-G, Yu C-J, Tsai M-F, et al. Survival of lung adenocarcinoma patients with malignant pleural effusion. Eur Respir J 2013; 41: 1409-1418

134 Soh J, Toyooka S, Aoe K, et al. Usefulness of EGFR mutation screening in pleural fluid to predict the clinical outcome of gefitinib treated patients with lung cancer. Int J Cancer 2006; 119: 2353-2358.

135 Zalcman G, Mazieres J, Margery J, et al. Bevacizumab for newly diagnosed pleural mesothelioma in the Mesothelioma Avastin Cisplatin Pemetrexed Study (MAPS): a randomised, controlled, open-label, phase 3 trial. Lancet 2015; 387: 1405-1414.

136 Gkiozos I, Tsagouli S, Charpidou A, et al. Levels of vascular endothelial growth factor in serum and pleural fluid are independent predictors of survival in advanced non-small cell lung cancer: results of a prospective study. Anticancer Res 2015; 35: 1129-1137.

137 Hsu IL, Su WC, Yan JJ, et al. Angiogenetic biomarkers in non-small cell lung cancer with malignant pleura effusion: correlations with patient survival and pleural effusion control. Lung Cancer 2009; 65: 371-376.

138 Edwards JG, Abrams KR, Leverment JN, et al. Prognostic factors for malignant mesothelioma in 142 patients: validation of CALGB and EORTC prognostic scoring systems. Thorax 2000; 55: 731-735.

139 Edwards JG, Swinson DE, Jones JL, et al. Tumor necrosis correlates with angiogenesis and is a predictor of poor prognosis in malignant mesothelioma. Chest 2003; 124: 1916-1923.

140 Rutter M, Saunders B, Wilkinson K, et al. Severity of inflammation is a risk factor for colorectal neoplasia in ulcerative colitis. Gastroenterology 2004; 126: 451-459.

141 Grivennikov SI, Greten FR, Karin M. Immunity, inflammation, and cancer. Cell 2010; 140: 883-899.

142 Fearon K, Strasser F, Anker SD, et al. Definition and classification of cancer cachexia: an international consensus. Lancet Oncol 2011; 12: 489-495.

143 Linton A, van Zandwijk N, Reid G, et al. Inflammation in malignant mesothelioma - friend or foe? Ann Cardiothorac Surg 2012; 1: 516-522.

144 McMillan DC. The systemic inflammation-based Glasgow Prognostic Score: a decade of experience in patients with cancer. Cancer Treat Rev 2013; 39: 534-540.

145 Pinato DJ, Mauri FA, Ramakrishnan R, et al. Inflammation-based prognostic indices in malignant pleural mesothelioma. J Thorac Oncol 2012; 7: 587-594.

146 Forrest L, McMillan D, McArdle C, et al. Evaluation of cumulative prognostic scores based on the systemic inflammatory response in patients with inoperable non-small-cell lung cancer. Br J Cancer 2003; 89: 1028-1030.

147 Sculier J-P, Chansky K, Crowley JJ, et al. The impact of additional prognostic factors on survival and their relationship with the anatomical extent of disease expressed by the 6th Edition of the TNM Classification of Malignant Tumors and the proposals for the 7th Edition. J Thorac Oncol 2008; 3: 457-466.

148 Paesmans M, Sculier J-P, Libert P, et al. Prognostic factors for survival in advanced non-small-cell lung cancer: univariate and multivariate analyses including recursive partitioning and amalgamation algorithms in 1,052 patients. The European Lung Cancer Working Party. J Clin Oncol 1995; 13: 1221-1230. 
Schmidt H, Bastholt L, Geertsen P, et al. Elevated neutrophil and monocyte counts in peripheral blood are associated with poor survival in patients with metastatic melanoma: a prognostic model. Br J Cancer 2005; 93: 273. Atzpodien J, Royston P, Wandert T, et al. Metastatic renal carcinoma comprehensive prognostic system. $\mathrm{Br} J$ Cancer 2003; 88: 348.

Lissoni P, Brivio F, Fumagalli L, et al. Efficacy of cancer chemotherapy in relation to the pretreatment number of lymphocytes in patients with metastatic solid tumors. Int J Biol Markers 2003; 19: 135-140.

Anraku M, Cunningham KS, Yun Z, et al. Impact of tumor-infiltrating T cells on survival in patients with malignant pleural mesothelioma. J Thorac Cardiovasc Surg 2008; 135: 823-829.

Yamada N, Oizumi S, Kikuchi E, et al. CD8+ tumor-infiltrating lymphocytes predict favorable prognosis in malignant pleural mesothelioma after resection. Cancer Immunol Immunother 2010; 59: 1543-1549.

Templeton AJ, McNamara MG, Šeruga B, et al. Prognostic role of neutrophil-to-lymphocyte ratio in solid tumors: a systematic review and meta-analysis. J Natl Canc Inst 2014; 106: 124.

Kao SCH, Pavlakis N, Harvie R, et al. High blood neutrophil-to-lymphocyte ratio is an indicator of poor prognosis in malignant mesothelioma patients undergoing systemic therapy. Clin Cancer Res 2010; 16: 5805-5813.

Clive AO, Kahan BC, Hooper CE, et al. Predicting survival in malignant pleural effusion: development and validation of the LENT prognostic score. Thorax 2014; 69: 1098-1104.

Linton A, Pavlakis N, O'Connell R, et al. Factors associated with survival in a large series of patients with malignant pleural mesothelioma in New South Wales. Br J Cancer 2014; 111: 1860-1869.

Suzuki K, Kadota K, Sima CS, et al. Chronic inflammation in tumor stroma is an independent predictor of prolonged survival in epithelioid malignant pleural mesothelioma patients. Cancer Immunol Immunother 2011; 60: $1721-1728$.

Hooper CE, Lyburn ID, Searle J, et al. The South West Area Mesothelioma and Pemetrexed trial: a multicentre prospective observational study evaluating novel markers of chemotherapy response and prognostication. $\mathrm{Br} \mathrm{J}$ Cancer 2015; 112: 1175-1182.

Lee YS, Nam HS, Lim JH, et al. Prognostic impact of a new score using neutrophil-to-lymphocyte ratios in the serum and malignant pleural effusion in lung cancer patients. BMC Cancer 2017; 17: 557.

Yao ZH, Tian GY, Yang SX, et al. Serum albumin as a significant prognostic factor in patients with malignant pleural mesothelioma. Tumour Biol 2014; 35: 6839-6845.

Yamagishi T, Fujimoto N, Nishi H, et al. Prognostic significance of the lymphocyte-to-monocyte ratio in patients with malignant pleural mesothelioma. Lung Cancer 2015; 90: 111-117.

Yao ZH, Tian GY, Wan YY, et al. Prognostic nutritional index predicts outcomes of malignant pleural mesothelioma. J Cancer Res Clin Oncol 2013; 139: 2117-2123.

Borasio P, Berruti A, Bille A, et al. Malignant pleural mesothelioma: clinicopathologic and survival characteristics in a consecutive series of 394 patients. Eur J Cardiothorac Surg 2008; 33: 307-313.

Christensen BC, Godleski JJ, Roelofs CR, et al. Asbestos burden predicts survival in pleural mesothelioma. Environ Health Perspect 2008; 116: 723-726.

Wolf AS, Richards WG, Tilleman TR, et al. Characteristics of malignant pleural mesothelioma in women. Ann Thorac Surg 2010; 90: 949-956.

Vigneswaran WT, Kircheva DY, Ananthanarayanan V, et al. Amount of epithelioid differentiation is a predictor of survival in malignant pleural mesothelioma. Ann Thorac Surg 2017; 103: 962-966.

Baud M, Strano S, Dechartres A, et al. Outcome and prognostic factors of pleural mesothelioma after surgical diagnosis and/or pleurodesis. J Thorac Cardiovasc Surg 2013; 145: 1305-1311.

Curran D, Sahmoud T, Therasse P, et al. Prognostic factors in patients with pleural mesothelioma: the European Organization for Research and Treatment of Cancer experience. J Clin Oncol 1998; 16: 145-152.

Francart J, Vaes E, Henrard S, et al. A prognostic index for progression-free survival in malignant mesothelioma with application to the design of phase II trials: a combined analysis of 10 EORTC trials. Eur J Cancer 2009; 45: 2304-2311.

1 Kataoka Y, Yamamoto Y, Otsuki T, et al. External validation of prognostic indices for overall survival of malignant pleural mesothelioma. Lung Cancer 113: 88-92.

Bille A, Krug LM, Woo KM, et al. Contemporary analysis of prognostic factors in patients with unresectable malignant pleural mesothelioma. J Thorac Oncol 2016; 11: 249-255.

Flores RM, Zakowski M, Venkatraman E, et al. Prognostic factors in the treatment of malignant pleural mesothelioma at a large tertiary referral center. J Thorac Oncol 2007; 2: 957-965.

Jennings CJ, Walsh PM, Deady S, et al. Malignant pleural mesothelioma incidence and survival in the Republic of Ireland 1994-2009. Cancer Epidemiol 2014; 38: 35-41.

Montanaro F, Rosato R, Gangemi M, et al. Survival of pleural malignant mesothelioma in Italy: a population-based study. Int J Cancer 2009; 124: 201-207. surveillance, epidemiology, and end results (SEER) study of 14,228 patients. PLoS One 2015; 10: e0145039.

Rena O, Boldorini R, Papalia E, et al. Persistent lung expansion after pleural talc poudrage in non-surgically resected malignant pleural mesothelioma. Ann Thorac Surg 2015; 99: 1177-1183.

8 Adel AM, Abdel Hafeez ZM, El Sheikh ET, et al. Malignant pleural mesothelioma: a retrospective analysis of clinicopathological and survival data. Thorac Cancer 2011; 2: 16-23.

Rahouma M, Aziz H, Ghaly G, et al. Survival in good performance malignant pleural mesothelioma patients; prognostic factors and predictors of response. Asian Pac J Cancer Prev 2017; 18: 2073-2078.

80 Wang S, Ma K, Wang Q, et al. The revised staging system for malignant pleural mesothelioma based on surveillance, epidemiology, and end results database. Int J Surg 2017; 48: 92-98.

81 Zhang A, Cao S, Jin S, et al. Elevated aspartate aminotransferase and monocyte counts predict unfavorable prognosis in patients with malignant pleural mesothelioma. Neoplasma 2017; 64: 114-122.

Kataoka Y, Yamamoto Y, Otsuki T, et al. A new prognostic index for overall survival in malignant pleural mesothelioma: the rPHS (regimen, PS, histology or stage) index. Jpn J Clin Oncol 2015; 45: 562-568.

Herndon JE, Green MR, Chahinian AP, et al. Factors predictive of survival among 337 patients with mesothelioma treated between 1984 and 1994 by the Cancer and Leukemia Group B. Chest 1998; 113: 723-731. 
Bottomley A, Coens C, Efficace F, et al. Symptoms and patient-reported well-being: do they predict survival in malignant pleural mesothelioma? A prognostic factor analysis of EORTC-NCIC 08983: randomized phase III study of cisplatin with or without raltitrexed in patients with malignant pleural mesothelioma. J Clin Oncol 2007; 25: $5770-5776$.

185 Creaney J, Francis RJ, Dick IM, et al. Serum soluble mesothelin concentrations in malignant pleural mesothelioma: relationship to tumor volume, clinical stage and changes in tumor burden. Clin Cancer Res 2011; 17: 1181-1189.

186 Arnold DT, De Fonseka D, Hamilton FW, et al. Prognostication and monitoring of mesothelioma using biomarkers: a systematic review. Br J Cancer 2017; 116: 731-741.

187 Hollevoet K, Nackaerts K, Gosselin R, et al. Soluble mesothelin, megakaryocyte potentiating factor, and osteopontin as markers of patient response and outcome in mesothelioma. J Thorac Oncol 2011; 6: 1930-1937.

188 Fennell DA, Parmar A, Shamash J, et al. Statistical validation of the EORTC prognostic model for malignant pleural mesothelioma based on three consecutive phase II trials. J Clin Oncol 2005; 23: 184-189.

189 Sandri A, Guerrera F, Roffinella M, et al. Validation of EORTC and CALGB prognostic models in surgical patients submitted to diagnostic, palliative or curative surgery for malignant pleural mesothelioma. $J$ Thorac Dis 2016; 8: 2121-2127.

190 Meniawy TM, Creaney J, Lake RA, et al. Existing models, but not neutrophil-to-lymphocyte ratio, are prognostic in malignant mesothelioma. Br J Cancer 2013; 109: 1813-1820.

191 Wang S, Ma K, Chen Z, et al. A nomogram to predict prognosis in malignant pleural mesothelioma. World J Surg 2017; 42: 2134-2142.

192 Brims FJ, Meniawy TM, Duffus I, et al. A novel clinical prediction model for prognosis in malignant pleural mesothelioma using decision tree analysis. J Thorac Oncol 2016; 11: 573-582.

193 Niho S, Kubota K, Yoh K, et al. Clinical outcome of chemoradiation therapy in patients with limited-disease small cell lung cancer with ipsilateral pleural effusion. J Thorac Oncol 2008; 3: 723-727.

194 Herrstedt J, Clementsen P, Hansen OP. Increased myelosuppression during cytostatic treatment and pleural effusion in patients with small cell lung cancer. Eur J Cancer 1992; 28A: 1070-1073.

195 Light RW. Pleural diseases. Philadelphia, Lippincott Williams \& Wilkins, 2007.

196 Adiguzel C, Bozkurt SU, Kaygusuz I, et al. Human herpes virus 8-unrelated primary effusion lymphoma-like lymphoma: report of a rare case and review of the literature. APMIS 2009; 117: 222-229.

197 Waddington TW, Aboulafia DM. Failure to eradicate AIDS-associated primary effusion lymphoma with high-dose chemotherapy and autologous stem cell reinfusion: case report and literature review. AIDS Patient Care STDS 2004; 18: 67-73.

198 Dabaja BS, Ha CS, Thomas DA, et al. The role of local radiation therapy for mediastinal disease in adults with T-cell lymphoblastic lymphoma. Cancer 2002; 94: 2738-2744.

199 Fujita A, Takabatake H, Tagaki S, et al. Combination chemotherapy in patients with malignant pleural effusions from non-small cell lung cancer: cisplatin, ifosfamide, and irinotecan with recombinant human granulocyte colony-stimulating factor support. Chest 2001; 119: 340-343.

200 Kitamura K, Kubota K, Ando M, et al. Bevacizumab plus chemotherapy for advanced non-squamous non-small-cell lung cancer with malignant pleural effusion. Cancer Chemother Pharmacol 2013; 71: 457-461.

201 Masago K, Fujimoto D, Fujita S, et al. Response to bevacizumab combination chemotherapy of malignant pleural effusions associated with non-squamous non-small-cell lung cancer. Mol Clin Oncol 2015; 3: 415-419.

202 Huang Z, Yan H, Chavan D, et al. Effective treatment of a patient with stage IV ovarian cancer: a case report. Oncol Lett 2018; 15: 588-591.

203 Lin JB, Lai FC, Li X, et al. Sequential treatment strategy for malignant pleural effusion in non-small cell lung cancer with the activated epithelial grow factor receptor mutation. J Drug Target 2017; 25: 119-124.

204 Jiang $\mathrm{T}$, Li A, Su C, et al. Addition of bevacizumab for malignant pleural effusion as the manifestation of acquired EGFR-TKI resistance in NSCLC patients. Oncotarget 2017; 8: 62648-62657.

205 Mori R, Fujimoto D, Ito M, et al. Bevacizumab for ramucirumab refractory malignant pleural effusion in non-small cell lung cancer: a case report and review of the literature. Oncotarget 2017; 8: 48521-48524.

206 Sebastian M, Kiewe P, Schuette W, et al. Treatment of malignant pleural effusion with the trifunctional antibody catumaxomab (removab) (anti-EpCAMxanti-CD3): results of a phase 1/2 study. J Immunother 2009; 32: 195-202.

207 Shen J, Zhu Z. Catumaxomab, a rat/murine hybrid trifunctional bispecific monoclonal antibody for the treatment of cancer. Curr Opin Mol Ther 2008; 10: 273-284.

208 Qi N, Li F, Li X, et al. Combination use of paclitaxel and avastin enhances treatment effect for the NSCLC patients with malignant pleural effusion. Medicine (Baltimore) 2016; 95: e5392.

209 Du N, Li X, Li F, et al. Intrapleural combination therapy with bevacizumab and cisplatin for non-small cell lung cancer-mediated malignant pleural effusion. Oncol Rep 2013; 29: 2332-2340.

210 Tamiya M, Tamiya A, Yamadori T, et al. Phase2 study of bevacizumab with carboplatin-paclitaxel for non-small cell lung cancer with malignant pleural effusion. Med Oncol 2013; 30: 676.

211 Salyer WR, Eggleston JC, Erozan YS. Efficacy of pleural needle biopsy and pleural fluid cytopathology in the diagnosis of malignant neoplasm involving the pleura. Chest 1975; 67: 536-539.

212 Nance KV, Shermer RW, Askin FB. Diagnostic efficacy of pleural biopsy as compared with that of pleural fluid examination. Mod Pathol 1991; 4: 320-324.

213 Prakash UB, Reiman HM. Comparison of needle biopsy with cytologic analysis for the evaluation of pleural effusion: analysis of 414 cases. Mayo Clin Proc 1985; 60: 158-164.

214 Froudarakis ME, Plojoux J, Kaspi E, et al. Positive pleural cytology is an indicator for visceral pleural invasion in metastatic pleural effusions. Clin Respir J 2018; 12: 1011-1016.

215 Renshaw AA, Dean BR, Antman KH, et al. The role of cytologic evaluation of pleural fluid in the diagnosis of malignant mesothelioma. Chest 1997; 111: 106-109.

216 Hooper C, Lee YC, Maskell N. BTS Pleural Guideline Group. Investigation of a unilateral pleural effusion in adults: British Thoracic Society Pleural Disease Guideline 2010. Thorax 2010; 65: Suppl. 2, ii4-i17. 
217 Henderson DW, Reid G, Kao SC, et al. Challenges and controversies in the diagnosis of mesothelioma: part 1. Cytology-only diagnosis, biopsies, immunohistochemistry, discrimination between mesothelioma and reactive mesothelial hyperplasia, and biomarkers. J Clin Pathol 2013; 66: 847-853.

218 Segal A, Sterrett GF, Frost FA, et al. A diagnosis of malignant pleural mesothelioma can be made by effusion cytology: results of a 20 year audit. Pathology 2013; 45: 44-48.

219 Rossi ED, Bizzarro T, Schmitt F, et al. The role of liquid-based cytology and ancillary techniques in pleural and pericardic effusions: an institutional experience. Cancer Cytopathol 2015; 123: 258-266.

220 Rivera MP, Mehta AC, Wahidi MM. Establishing the diagnosis of lung cancer: diagnosis and management of lung cancer, 3rd ed: American College of Chest Physicians evidence-based clinical practice guidelines. Chest 2013; 143: 5 Suppl., e142S-e165S.

221 Garcia LW, Ducatman BS, Wang HH. The value of multiple fluid specimens in the cytological diagnosis of malignancy. Mod Pathol 1994; 7: 665-668.

222 Rakha EA, Patil S, Abdulla K, et al. The sensitivity of cytologic evaluation of pleural fluid in the diagnosis of malignant mesothelioma. Diagn Cytopathol 2010; 38: 874-879.

223 Pinelli V, Laroumagne S, Sakr L, et al. Pleural fluid cytological yield and visceral pleural invasion in patients with epithelioid malignant pleural mesothelioma. J Thorac Oncol 2012; 7: 595-598.

224 Abouzgheib W, Bartter T, Dagher H, et al. A prospective study of the volume of pleural fluid required for accurate diagnosis of malignant pleural effusion. Chest 2009; 135: 999-1001.

225 Thomas SC, Davidson LR, McKean ME. An investigation of adequate volume for the diagnosis of malignancy in pleural fluids. Cytopathology 2011; 22: 179-183.

226 Rooper LM, Ali SZ, Olson MT. A minimum fluid volume of $75 \mathrm{~mL}$ is needed to ensure adequacy in a pleural effusion: a retrospective analysis of 2540 cases. Cancer Cytopathol 2014; 122: 657-665.

227 Swiderek J, Morcos S, Donthireddy V, et al. Prospective study to determine the volume of pleural fluid required to diagnose malignancy. Chest 2010; 137: 68-73.

228 Porcel JM, Quiros M, Gatius S, et al. Examination of cytological smears and cell blocks of pleural fluid: complementary diagnostic value for malignant effusions. Rev Clin Esp 2017; 217: 144-148.

229 Dekker A, Bupp PA. Cytology of serous effusions: an investigation into the usefulness of cell blocks versus smears. Am J Clin Pathol 1978; 70: 855-860.

230 Galateau-Salle F, Churg A, Roggli V, et al. The 2015 World Health Organization Classification of Tumors of the Pleura: advances since the 2004 classification. J Thorac Oncol 2016; 11: 142-154.

231 Husain AN, Colby T, Ordonez N, et al. Guidelines for pathologic diagnosis of malignant mesothelioma: 2012 update of the consensus statement from the International Mesothelioma Interest Group. Arch Pathol Lab Med 2013; 137: 647-667.

232 Husain AN, Colby TV, Ordonez NG, et al. Guidelines for pathologic diagnosis of malignant mesothelioma: 2017 update of the consensus statement from the International Mesothelioma Interest Group. Arch Pathol Lab Med 2017; 142: 89-108.

233 Karpathiou G, Stefanou D, Froudarakis ME. Pleural neoplastic pathology. Respir Med 2015; 109: 931-943.

234 Yang Y, Liu YL, Shi HZ. Diagnostic accuracy of combinations of tumor markers for malignant pleural effusion: an updated meta-analysis. Respiration 2017; 94: 62-69.

235 Katz RL, Raval P, Manning JT, et al. A morphologic, immunologic, and cytometric approach to the classification of non-Hodgkin's lymphoma in effusions. Diagn Cytopathol 1987; 3: 91-101.

236 Simsir A, Fetsch P, Stetler-Stevenson M, et al. Immunophenotypic analysis of non-Hodgkin's lymphomas in cytologic specimens: a correlative study of immunocytochemical and flow cytometric techniques. Diagn Cytopathol 1999; 20: 278-284.

237 Pillai V, Cibas ES, Dorfman DM. A simplified flow cytometric immunophenotyping procedure for the diagnosis of effusions caused by epithelial malignancies. Am J Clin Pathol 2013; 139: 672-681.

238 Davidson B, Dong HP, Berner A, et al. Detection of malignant epithelial cells in effusions using flow cytometric immunophenotyping: an analysis of 92 cases. Am J Clin Pathol 2002; 118: 85-92.

239 Acosta M, Pereira J, Arroz M. Screening of carcinoma metastasis by flow cytometry: a study of 238 cases. Cytometry B Clin Cytom 2016; 90: 289-294.

240 Tse HT, Gossett DR, Moon YS, et al. Quantitative diagnosis of malignant pleural effusions by single-cell mechanophenotyping. Sci Transl Med 2013; 5: 212ra163.

241 Berg KB, Churg A. GATA3 immunohistochemistry for distinguishing sarcomatoid and desmoplastic mesothelioma from sarcomatoid carcinoma of the lung. Am J Surg Pathol 2017; 41: 1221-1225.

242 Churg A, Sheffield BS, Galateau-Salle F. New markers for separating benign from malignant mesothelial proliferations: are we there yet? Arch Pathol Lab Med 2016; 140: 318-321.

243 Hwang HC, Sheffield BS, Rodriguez S, et al. Utility of BAP1 immunohistochemistry and p16 (CDKN2A) FISH in the diagnosis of malignant mesothelioma in effusion cytology specimens. Am J Surg Pathol 2016; 40: $120-126$.

244 Cigognetti M, Lonardi S, Fisogni S, et al. BAP1 (BRCA1-associated protein 1) is a highly specific marker for differentiating mesothelioma from reactive mesothelial proliferations. Mod Pathol 2015; 28: 1043-1057.

245 Hiroshima K, Wu D, Hasegawa M, et al. Cytologic differential diagnosis of malignant mesothelioma and reactive mesothelial cells with FISH analysis of p16. Diagn Cytopathol 2016; 44: 591-598.

246 Paintal A, Raparia K, Zakowski MF, et al. The diagnosis of malignant mesothelioma in effusion cytology: a reappraisal and results of a multi-institution survey. Cancer Cytopathol 2013; 121: 703-707.

247 Valente K, Blackham AU, Levine E, et al. A histomorphologic grading system that predicts overall survival in diffuse malignant peritoneal mesothelioma with epithelioid subtype. Am J Surg Pathol 2016; 40: 1243-1248.

248 Habougit C, Trombert-Paviot B, Karpathiou G, et al. Histopathologic features predict survival in diffuse pleural malignant mesothelioma on pleural biopsies. Virchows Arch 2017; 470: 639-646.

249 Kadota K, Suzuki K, Colovos C, et al. A nuclear grading system is a strong predictor of survival in epitheloid diffuse malignant pleural mesothelioma. Mod Pathol 2012; 25: 260-271.

250 Ghanim B, Klikovits T, Hoda MA, et al. Ki67 index is an independent prognostic factor in epithelioid but not in non-epithelioid malignant pleural mesothelioma: a multicenter study. Br J Cancer 2015; 112: 783-792. 
Hatoum H, Lourdes Y, Dhillon SS, et al. Adequacy of malignant pleural effusion for epidermal growth factor receptor mutation analysis using the pyrosequencing method. Pleura (Thousand Oaks) 2015; 2.

252 Carter J, Miller JA, Feller-Kopman D, et al. Molecular profiling of malignant pleural effusion in metastatic non-small-cell lung carcinoma the effect of preanalytical factors. Ann Am Thorac Soc 2017; 14: 1169-1176.

253 Shin S, Kim J, Kim Y, et al. Assessment of real-time PCR method for detection of EGFR mutation using both supernatant and cell pellet of malignant pleural effusion samples from non-small-cell lung cancer patients. Clin Chem Lab Med 2017; 55: 1962-1969.

254 Tang Y, Wang Z, Li Z, et al. High-throughput screening of rare metabolically active tumor cells in pleural effusion and peripheral blood of lung cancer patients. Proc Natl Acad Sci USA 2017; 114: 2544-2549.

255 Rahman NM, Ali NJ, Brown G, et al. Local anaesthetic thoracoscopy: British Thoracic Society Pleural Disease Guideline 2010. Thorax 2010; 65: Suppl. 2, ii54-ii60.

256 Bibby AC, Maskell NA. Pleural biopsies in undiagnosed pleural effusions; Abrams vs image-guided vs thoracoscopic biopsies. Curr Opin Pulm Med 2016; 22: 392-398.

257 Miyoshi S, Sasada S, Izumo T, et al. Diagnostic utility of pleural fluid cell block versus pleural biopsy collected by flex-rigid pleuroscopy for malignant pleural disease: a single center retrospective analysis. PLoS One 2016; 11: e0167186.

258 Davies HE, Nicholson JE, Rahman NM, et al. Outcome of patients with nonspecific pleuritis/fibrosis on thoracoscopic pleural biopsies. Eur J Cardiothorac Surg 2010; 38: 472-477.

259 Gunluoglu G, Olcmen A, Gunluoglu MZ, et al. Long-term outcome of patients with undiagnosed pleural effusion. Arch Bronconeumol 2015; 51: 632-636.

260 Venekamp LN, Velkeniers B, Noppen M. Does 'idiopathic pleuritis' exist? Natural history of non-specific pleuritis diagnosed after thoracoscopy. Respiration 2005; 72: 74-78.

261 Janssen JP, Ramlal S, Mravunac M. The long-term follow-up of exudative pleural effusion after nondiagnostic thoracoscopy. J Bronchol 2004; 11: 169-174

262 Yang Y, Wu YB, Wang Z, et al. Long-term outcome of patients with nonspecific pleurisy at medical thoracoscopy. Respir Med 2017; 124: 1-5.

263 Siravegna G, Marsoni S, Siena S, et al. Integrating liquid biopsies into the management of cancer. Nat Rev Clin Oncol 2017; 14: 531-548.

264 Cappellesso R, Galasso M, Nicole L, et al. miR-130A as a diagnostic marker to differentiate malignant mesothelioma from lung adenocarcinoma in pleural effusion cytology. Cancer 2017; 125: 635-643.

265 Karachaliou N, Mayo-de las Casas C, Queralt C, et al. Association of EGFR L858R mutation in circulating free DNA with survival in the EURTAC trial. JAMA Oncol 2015; 1: 149-157.

266 Mok T, Wu YL, Lee JS, et al. Detection and dynamic changes of EGFR mutations from circulating tumor DNA as a predictor of survival outcomes in NSCLC patients treated with first-line intercalated erlotinib and chemotherapy. Clin Cancer Res 2015; 21: 3196-3203.

267 Oxnard GR, Thress KS, Alden RS, et al. Association between plasma genotyping and outcomes of treatment with osimertinib (AZD9291) in advanced non-small-cell lung cancer. J Clin Oncol 2016; 34: 3375-3382.

268 Sacher AG, Paweletz C, Dahlberg SE, et al. Prospective validation of rapid plasma genotyping for the detection of EGFR and KRAS mutations in advanced lung cancer. JAMA Oncol 2016; 2: 1014-1022.

269 Muraoka T, Soh J, Toyooka S, et al. The degree of microRNA-34b/c methylation in serum-circulating DNA is associated with malignant pleural mesothelioma. Lung Cancer 2013; 82: 485-490.

270 Santarelli L, Staffolani S, Strafella E, et al. Combined circulating epigenetic markers to improve mesothelin performance in the diagnosis of malignant mesothelioma. Lung Cancer 2015; 90: 457-464.

271 Kirschner MB, Cheng YY, Badrian B, et al. Increased circulating miR-625-3p: a potential biomarker for patients with malignant pleural mesothelioma. J Thorac Oncol 2012; 7: 1184-1191. 